\title{
miR-146b-5p inhibits tumorigenesis and metastasis of gallbladder cancer by targeting Toll-like receptor 4 via the nuclear factor-kB pathway
}

\author{
BIN OUYANG ${ }^{1,2}$, NINGFENG PAN ${ }^{3}$, HAIFENG ZHANG ${ }^{2}$, CHUANMING XING $^{2}$ and WU JI ${ }^{1}$ \\ ${ }^{1}$ Research Institute of General Surgery, Jinling Hospital, The First School of Clinical Medicine, \\ Southern Medical University, Nanjing, Jiangsu 210002; Departments of ${ }^{2}$ General Surgery \\ and ${ }^{3}$ Neurology, Nanjing Central Hospital, Nanjing, Jiangsu 210018, P.R. China
}

Received September 24, 2019; Accepted June 29, 2020

DOI: $10.3892 /$ or.2021.7966

\begin{abstract}
Gallbladder cancer (GBC) is a carcinoma of the biliary tract, which is common in developing countries and is associated with a high fatality rate. The aim of the present study was to investigate the mechanisms underlying the occurrence and development of GBC. A decrease in the expression of miR-146b-5p and an increase in the expression of its target gene Toll-like receptor 4 (TLR4) were first observed in GBC tissues. Further study demonstrated that an increase in TLR4 expression caused by a decrease in $\mathrm{miR}-146 \mathrm{~b}-5 \mathrm{p}$ expression led to activation of nuclear factor (NF) $-\kappa B$ signaling. GBC cells were cultured in vitro, and it was observed that overexpression of miR-146b-5p effectively inhibited their viability, proliferation, migration and invasion, and increased their apoptosis. Using a BALB/c nude mouse xenograft model, it was demonstrated that overexpression of miR-146b-5p was sufficient to reduce tumor volume and alleviate pathological characteristics. Overall, the results of the present study indicated that the decrease in the expression of miR-146b-5p increased TLR4 expression and indirectly activated the $\mathrm{NF}-\kappa \mathrm{B}$ signaling pathway, thereby regulating the development of GBC.
\end{abstract}

\section{Introduction}

Gallbladder cancer (GBC) is a rare but fatal cancer of the biliary tract, which is often encountered in developing countries. The variation in the incidence of GBC across different regions and races suggests that genetic and environmental factors may

Correspondence to: $\mathrm{Dr} \mathrm{Wu} \mathrm{Ji}$, Research Institute of General Surgery, Jinling Hospital, The First School of Clinical Medicine, Southern Medical University, 305 Eastern Zhongshan Road, Nanjing, Jiangsu 210002, P.R. China

E-mail: jiwuvip@126.com

Key words: gallbladder cancer, miR-146b-5p, proliferation, apoptosis, Toll-like receptor 4 play an important role in this type of cancer $(1,2)$. Previous studies have demonstrated that a number of factors may induce GBC formation, including chronic gallbladder infections, specific chemicals, exposure to heavy metals, even multiple dietary factors $(3,4)$. Familial gallstones, long-term tobacco exposure and excessive intake of fried foods may increase the risk of GBC (5). Treatment of GBC is often challenging, mainly because it is difficult to diagnose at its early stages. Furthermore, a propensity for liver infiltration and metastasis is an important reason for the poor prognosis (6). Surgical treatment is currently the mainstay of treatment for patients with GBC (7). Similar to other tumors, GBC is a disease involving a variety of genetic factors. However, our knowledge of the genetic and molecular changes associated with GBC is currently limited $(8,9)$ and there is an urgent need to elucidate the specific processes and mechanisms involved in its early occurrence and development.

MicroRNAs (miRNAs) are a group of endogenous, small non-coding RNAs, 18-25 nucleotides in length, that are highly conserved across species (10-12). miRNAs bind to the 3'-untranslated region (UTR) of their target mRNAs to cause their degradation or inhibit their transcription. Accumulating evidence indicates that miRNAs play key roles in regulating various biological processes, including cell proliferation, differentiation and apoptosis $(13,14)$. In addition, miRNAs have become a key focus in cancer research in recent years, and some miRNAs have been shown to inhibit or promote tumorigenesis $(15,16)$. Previous studies have demonstrated that, during the development and progression of GBC, the expression patterns of some miRNAs may change. For example, Kono et al demonstrated that aberrant expression of miR-155 markedly increased the proliferation and invasion ability of GBC cells, and the survival prognosis of GBC patients with high levels of miR-155 was worse compared with that of patients with lower levels of miR-155 (17). miR-1, miR-24 and miR-135 were also reported to play important roles in GBC as tumor suppressors (18-20). In most cases of primary GBC, downregulation of miR-335 may be associated with tumor invasiveness (21). miR-146b-5p has been shown to be abnormally expressed in a variety of malignancies in humans, including gastric cancer, thyroid cancer, osteosarcoma and 
glioma (22-25). Although abnormal miR-146b-5p expression levels have been reported in GBC, the specific role and mechanism of action of miR-146b-5p in the development of GBC requires further investigation (26).

Activation of the Toll-like receptor 4 (TLR4) pathway leads to activation of IRE3, NF- $\mathrm{KB}$ and mitogen-activated protein kinase via MyD88-dependent and non-dependent pathways, and then induces the expression of type II IFN (IFN- $\gamma$ ) and pro-inflammatory cytokines (27-30). Activation of TLR4 was previously considered to be primarily involved in the innate immune response to bacterial infection (31). However, recent research has demonstrated that activation of TLR4 participates in the physiological processes of various cancer cells, and is associated with the metastasis of certain cancers (32-36). In some cancer cells (e.g., breast cancer cells), TLR4 functions as a regulator through a dual TP53-dependent role. In the case of TP53 expression, activated TLR4 increases INF- $\gamma$ secretion and inhibition of breast cancer cell proliferation, thereby exerting an anticancer effect. However, when TP53 is mutated, activated TLR4 induces the secretion of growth factors to promote breast cancer cell proliferation and exerts a cancer-promoting effect (37).

In the present study, the level of miR-146b-5p was detected in 60 groups of human GBC and normal tissues. In addition, the expression levels of miR-146b-5p were compared between human GBC cells cultured in vitro and gallbladder epithelial cells. Furthermore, the effects of miR-146b-5p overexpression on the proliferation, migration, invasion and apoptosis of GBC cells were investigated. Bioinformatics analysis identified TLR4 as the possible target gene of miR-146b-5p. Therefore, the mRNA and protein levels of TLR4 were investigated in GBC tissues and cells. By overexpressing or inhibiting the expression of miR-146b-5p, it was investigated whether there is a correlation between the expression level of TLR4 and that of miR-146b-5p, and how the overexpression of miR-146b-5p and TLR4 affects the proliferation, migration and invasion ability of GBC cells. It was also investigated whether these effects are mediated via regulation of the NF- $\mathrm{KB}$ signaling pathway. In vivo experiments were also performed to examine the effects of miR-146b-5p overexpression on GBC cell proliferation and apoptosis.

\section{Materials and methods}

Patients and clinical samples. GBC samples and adjacent normal gallbladder tissue samples were acquired from 60 surgical patients, and all specimens had been clinically diagnosed and histologically confirmed at the Jinling Hospital between July 2017 and June 2018. Patient informed consent for participation was obtained at the time of the study. The study protocol was approved by the Ethics Committee of Southern Medical University (no. 2018-SR-052). Immediately after surgery, clinical samples were divided into two groups: One group of samples was immediately fixed in $4 \%$ paraformaldehyde and then embedded in paraffin for later experiments, whereas the remaining samples were placed in liquid nitrogen and preserved at $-80^{\circ} \mathrm{C}$ to be further used for mRNA and protein extraction.

Reverse transcription-quantitative PCR (RT-qPCR) assay. TRIzol ${ }^{\circledR}$ reagent (Invitrogen; Thermo Fisher Scientific,Inc.) was used to extract total RNA from tissues and cells, according to the manufacturer's protocols. For each sample, $1 \mu \mathrm{g}$ RNA was reversely transcribed into complementary DNA (cDNA) using the Reverse Transcription System Kit (Applied Biosystems; Thermo Fisher Scientific, Inc.). qPCR assay was used to examine the expression of miR-146b-5p and TLR4. U6 was used as an internal reference gene. The thermocycling conditions were as follows: $95^{\circ} \mathrm{C}$ for $5 \mathrm{~min}$, followed by 40 cycles at $95^{\circ} \mathrm{C}$ for $10 \mathrm{sec}$ and at $60^{\circ} \mathrm{C}$ for $30 \mathrm{sec}$. The primers used were as follows: miR-146b-5p: 5'-TGAACTGAATTCATG GGTT-3' (sense) and 5'-ATCTTGAGCTCCTCCGAAG-3' (antisense); TLR4: 5'-AGCACTTCATCCAGAGCCGC-3' (sense) and 5'-CGGTACAGCTCCACCTGCTG-3' (antisense); U6: 5'-GCTTCGGCAGCACATATACTAAAAT-3' (sense) and 5'-CGCTTCAGAATTTGCGTGTCAT-3' (antisense). The gene expression levels were calculated using the $2^{-\Delta \Delta \mathrm{Cq}}$ method (16).

Cell cultures. The human GBC cell lines NOZ and GBC-SD were purchased from Shanghai Institutes for Biological Sciences, Chinese Academy of Sciences (Shanghai, China). The normal human gallbladder epithelium cell line HGBEC was obtained by cell isolation and culture. GBC-SD cells were cultured in RPMI-1640 medium (Gibco; Thermo Fisher Scientific, Inc.), NOZ cells were maintained in William's E Medium (Gibco; Thermo Fisher Scientific, Inc.) and HGBEC cells were cultured in DMEM (Gibco; Thermo Fisher Scientific, Inc.) supplemented with $10 \%$ FBS (Thermo Fisher Scientific, Inc.), penicillin and streptomycin $(100 \mu \mathrm{g} / \mathrm{ml})$ in an incubator with $5 \% \mathrm{CO}_{2}$ at $37^{\circ} \mathrm{C}$.

Cell transfection. For upregulation or suppression of miR-146b-5p, all the plasmids were procured from GenePharma. The plasmids were marked with green fluorescent protein (GFP) and the miR-146b-5p mimics, inhibitors and the negative controls (NC mimics and NC inhibitors) were synthesized by GenePharma. The sequences were as follows: miR-146b-5p mimics, sense 5'-UGAGAACUGAAUUCCAUGGGUU-3' and antisense 5'-CCCAUGGAAUUCAGUUCUCAUU-3'; and miR-146b-5p mimics NC, sense 5'-UUCUCCGAACGUGUC ACGUTT-3' and antisense 5'-ACGUGACACGUUCGGAGA ATT-3'. miR-146b-5p inhibitors: 5'-AACCCAUGGAAUUCA GUUCUCA-3'; miR-146b-5p inhibitors NC: 5'-CAGUACUUU UGUGUAGUACAA-3'. Cell transfection was performed with Lipofectamine $^{\mathrm{TM}} 2000$ (Invitrogen; Thermo Fisher Scientific, Inc.) as per the manufacturer's recommendations. RT-PCR analysis and green fluorescence microscopy were performed to assess the transfection efficiency.

Cell Counting Kit- 8 (CCK-8) assay. The CCK- 8 assay (Beyotime Institute of Biotechnology) was used to detect the proliferation and activity of GBC cells according to the manufacturer's protocol. Cells were inoculated into a 96-well plate at $1 \times 10^{5}$ cells/well and cultured for 24,48 and $72 \mathrm{~h}$. Subsequently, the cells were incubated with CCK-8 solution with $5 \% \mathrm{CO}_{2}$ at $37^{\circ} \mathrm{C}$ for $2-3 \mathrm{~h}$. A microplate reader (Bio-Rad Laboratories, Inc.) was used to measure the absorbance at $450 \mathrm{~nm}$.

Cell colony formation assay. Cells in the logarithmic growth phase were digested by $0.25 \%$ trypsin and counted. A cell 
suspension was prepared with DMEM and the cell density reached $1 \times 10^{6}$ cells per liter. Low melting point agarose (1.2\%) mixed with equal amount of DMEM was added to the Petri dish to cool and solidify as the bottom agar. The cell suspension $(0.2 \mathrm{ml})$ was added to the mixture of $0.7 \%$ agarose and DMEM, and then coagulated in the Petri dish as the upper agar. The cells were cultured for 2 weeks with $5 \% \mathrm{CO}_{2}$ at $37^{\circ} \mathrm{C}$. The number of cell clones was observed under an inverted microscope at a magnification of x40 (Olympus Corporation) and the colony formation rate was calculated.

Western blot assay. Lysis buffer (Thermo Fisher Scientific, Inc.) was used to lyse cells/tissues, and the protein concentration in the lysates was determined using a BCA Protein Assay Kit (Beyotime Institute of Biotechnology) according to the manufacturer's instructions. Equal amounts of protein $(10 \mathrm{mg})$ were resolved by $12 \%$ SDS-PAGE and transferred to PVDF membranes (EMD Millipore). The membranes were blocked with 5\% BSA mixed with Tris-buffered saline/0.1\% Tween-20 (Beyotime Institute of Biotechnology), and then incubated with primary antibodies overnight at $4^{\circ} \mathrm{C}$. The primary antibodies used in the present study were obtained from Abcam and were as follows: Anti-GAPDH (cat. no. ab181602; 1:2,000), anti-PCNA (cat. no. ab18197; 1:1,000), anti-cleaved-caspase-3 (cat. no. ab2302; 1:1,000), anti-caspase-3 (cat. no. ab13847; 1:1,000), anti-cleaved-caspase-9 (ab2304; 1:1,000), anti-caspase-9 (cat. no. ab52298; 1:1,000), anti-Bax (cat. no. ab32503; 1:1,000), anti-Bcl-2 (cat. no. ab32124; 1:1,000), anti-cyclooxygenase-2 (anti-COX-2; cat. no. ab23672; $1: 1,000)$, anti-matrix metallopeptidase (MMP)-2 (cat. no. ab86607; 1:1,000), anti-MMP-9 (cat. no. ab76003; 1:1,000), anti-TLR4 (cat. no. ab13556; 1:1,000), anti-inhibitor of nuclear factor $(\mathrm{NF})-\kappa \mathrm{B}$ (anti-I $\mathrm{B} \alpha$; cat. no. ab32518; 1:1,000), anti-phosphorylated (p)-IкB $\alpha$ (cat. no. ab133462; 1:1,000), anti-p-NF-кB (cat. no. ab222494; 1:1,000) and anti-Histone H3 (cat. no. ab1791; 1:1,000). The membranes were then incubated with corresponding secondary antibodies for $2 \mathrm{~h}$ at room temperature. The protein bands were derived from the same membrane and exposed using a Super Signal ECL kit (EMD Millipore) in a western blot detection instrument and quantified by gray level analysis relative to GAPDH or $\mathrm{H} 3$.

Apoptosis detection by Annexin V-FITC staining. The cultured cells under different treatments were washed three times with cold PBS. The cells were then suspended in $50 \mu \mathrm{l}$ binding buffer and stained with Annexin V-FITC and propidium iodide for $15 \mathrm{~min}$ at room temperature in the dark. Then, the cell suspension was gently blended after adding $100 \mu \mathrm{l}$ of binding buffer, and the percentage of apoptotic cells was detected by flow cytometry (LSR2; BD Biosciences) using FlowJo 10.06 software (FlowJo LLC).

Wound healing assay. Cells $\left(1 \times 10^{6}\right)$ were inoculated on a 6 -well plate. After the cells had reached a confluence of $\sim 100 \%$, a linear scratch was created in the cell monolayer with the tip of a 10- $\mu 1$ micropipette. The detached cells were gently washed off with $1 \mathrm{X}$ PBS and the remaining cells were cultured in serum-free medium with $5 \% \mathrm{CO}_{2}$ at $37^{\circ} \mathrm{C}$. Finally, images were captured at 0 and $48 \mathrm{~h}$ under a light microscope at a magnification of x200 (Olympus Corporation).
Transwell migration and invasion assays. Transwell migration and invasion experiments were performed using Boyden chambers (BD Biosciences). Cells $\left(1 \times 10^{6}\right)$ were cultured in serum-free medium for $24 \mathrm{~h}$ and digested with trypsin. Then, BSA-containing serum-free medium was used to re-suspend the cells to a cell density of $5 \times 10^{5} / \mathrm{ml}$. A total of $100 \mu \mathrm{l}$ of cell suspension was added to the upper chamber without Matrigel (for the migration assay) or pre-coated with Matrigel (for the invasion assay) at $37^{\circ} \mathrm{C}$ for $30 \mathrm{~min}$ (BD Biosciences); $600 \mu \mathrm{l}$ DMEM supplemented with $20 \%$ FBS was added to the lower chamber. After $24 \mathrm{~h}$ of conventional culture at $37^{\circ} \mathrm{C}$, the chamber was removed, washed twice with PBS, then fixed with $4 \%$ formaldehyde at $37^{\circ} \mathrm{C}$ for $30 \mathrm{~min}$. After $20 \mathrm{~min}$ of staining with $0.1 \%$ crystal violet solution at $37^{\circ} \mathrm{C}$, the cells in the upper chamber were wiped off and the chamber was washed three times with PBS. The cells were observed and counted under a microscope (Olympus Corporation) at a magnification of x200 in five random fields of view.

Luciferase reporter assay. 3'-UTR fragments of TLR4 containing wild-type or mutant miR-146b-5p-binding sites were inserted into the psiCHECK-2 plasmids (Promega Corporation) to produce TLR4-WT and TLR4-Mut constructs. Cells were co-transfected with indicated constructs and miR-146b-5p mimic or NC mimic by using Lipofectamine ${ }^{\mathrm{TM}}$ 2000 (Invitrogen; Thermo Fisher Scientific, Inc.) following the manufacturer's instructions. At $48 \mathrm{~h}$ post-transfection, luciferase activity was determined with the Dual-Luciferase Reporter Assay System (Promega Corporation) according to the manufacturer's instructions and normalized to Renilla luciferase activity.

Immunohistochemical analysis. The tissue sections were maintained at room temperature for $1 \mathrm{~h}$, then immersed in xylene for $10 \mathrm{~min}$ to deparaffinize. The sections were hydrated with different concentration gradients of ethanol. Subsequently, the slides were immersed in sodium citrate buffer ( $\mathrm{pH}$ 6.0) and boiled for $30 \mathrm{~min}$, followed by incubation with anti-TLR4 (ab13867, 1:1,000, Abcam) and anti-Ki-67 antibodies (ab15580, 1:1,000, Abcam) at $37^{\circ} \mathrm{C}$ according to the immunohistochemistry protocol. The sections were observed under a light microscope (CX23; Olympus Corporation) and images were captured at a magnification of $\mathrm{x} 200$.

Immunofluorescence analysis. The cells were washed with PBS and fixed in 1\% formalin in PBS at room temperature for $10 \mathrm{~min}$. After fixing, the cells were washed in PBS three times ( $5 \mathrm{~min}$ per wash), and incubated for $3 \mathrm{~min}$ at $37^{\circ} \mathrm{C}$ in a solution of $0.01 \%$ Triton $\mathrm{X}-100$ in PBS, followed by washing three times in PBS for 5 min per wash and blocking in $10 \%$ goat serum (Gibco; Thermo Fisher Scientific, Inc.) for $1 \mathrm{~h}$ at room temperature. The cells were then incubated overnight at $4^{\circ} \mathrm{C}$ with primary antibody against TLR4 (cat. no. ab13556; 1:1,000, Abcam). On the following day, the cells were washed in PBS three times (5 min per wash) and incubated with secondary antibody (ab150081, 1:1,000, Abcam) for $2 \mathrm{~h}$ at room temperature. After incubation, the cells were rinsed in PBS three times (5 min per wash) and mounted in $50 \%$ triglyceride. 
A เి

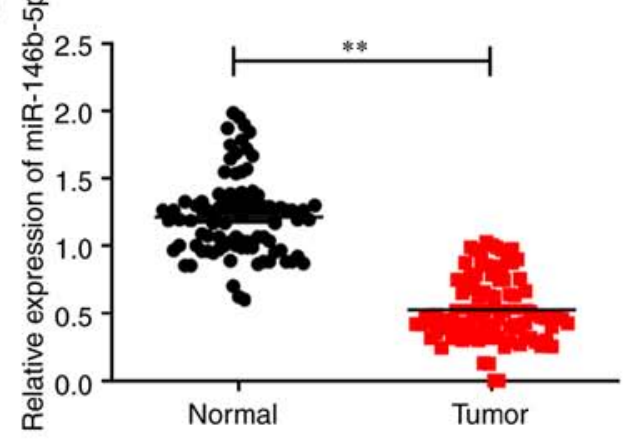

C

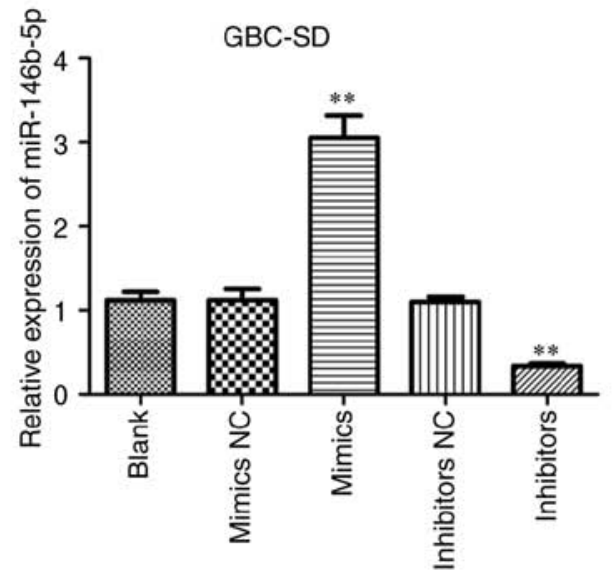

GBC-SD Blank

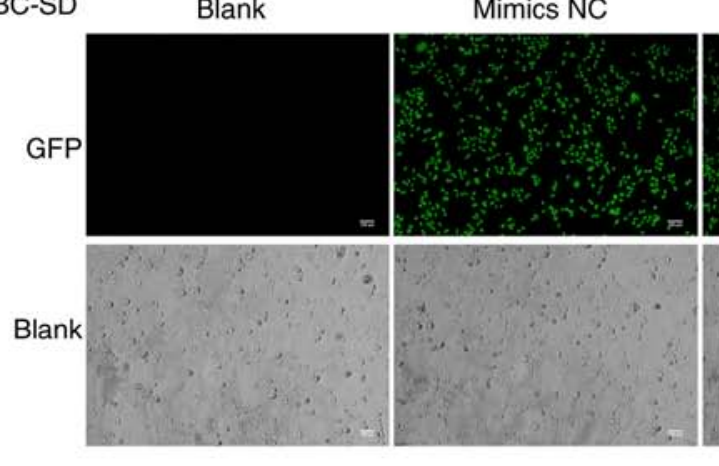

NOZ

Blank

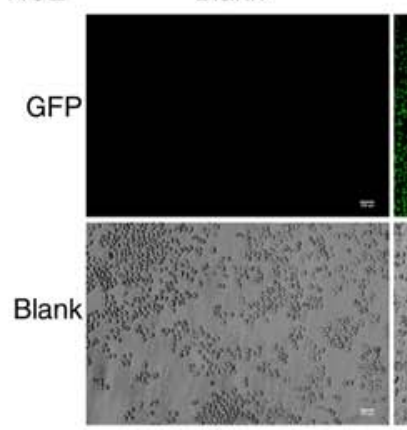

Mimics NC

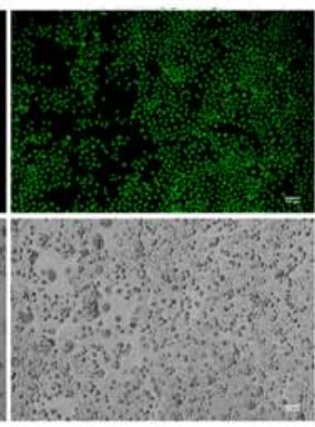

$B$ เก
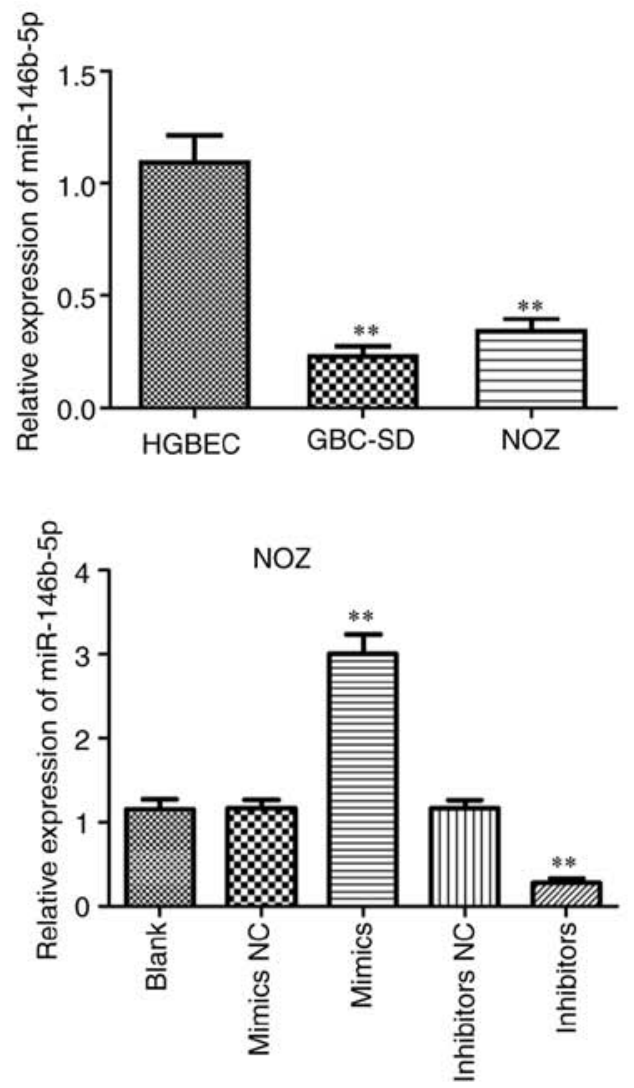

Mimics

Inhibitors NC

Inhibitors
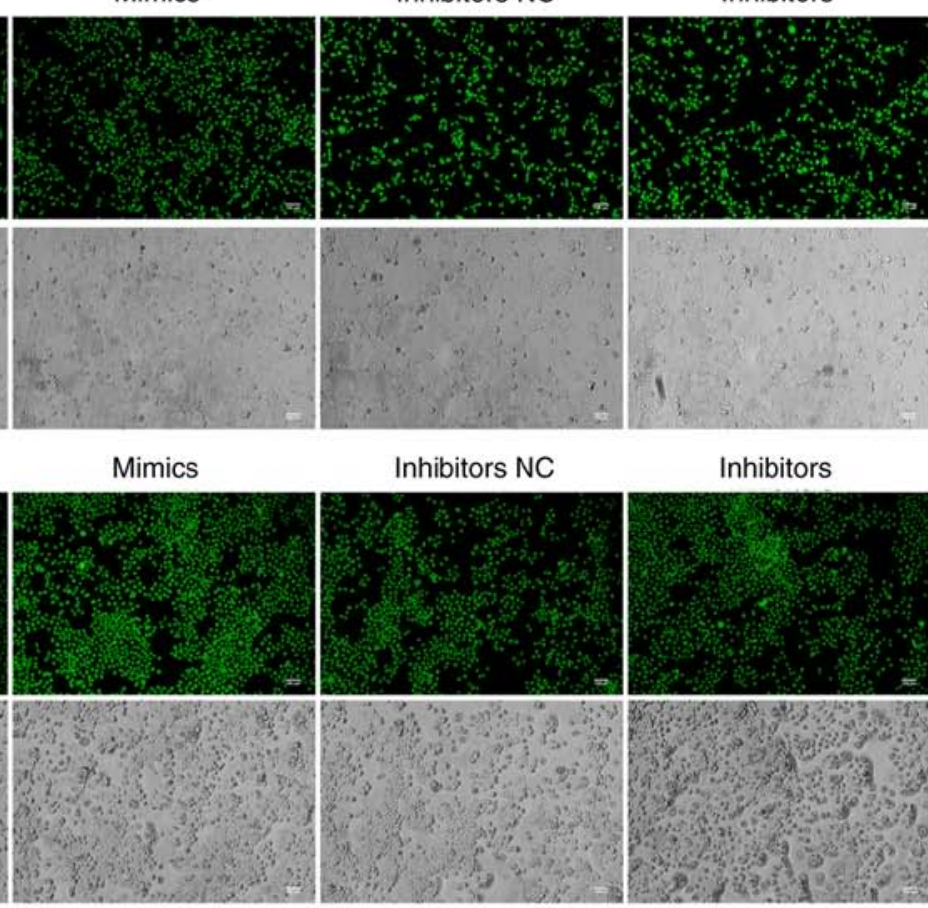

Inhibitors

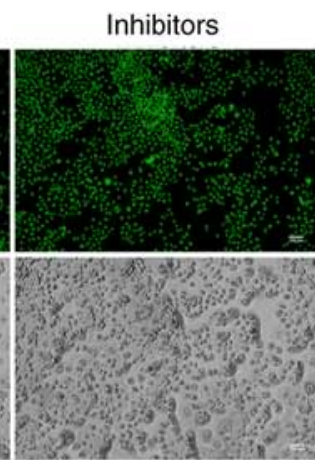

Figure 1. Reduced expression of miR-146b-5p in GBC tissues and cells. (A) The expression of miR-146b-5p was decreased in GBC tissues compared with normal tissues as determined by RT-qPCR analysis $(\mathrm{n}=80)$. (B) RT-qPCR indicated a reduction in miR-146b-5p levels in GBC cells compared to gallbladder epithelial cells. (C) Detection of the efficiency of overexpression and inhibition of miR-146b-5p in two different GBC cell lines by RT-qPCR. (D) The fluorescent signal of GFP was detected in miR-146b-5p mimics NC group, miR-146b-5p mimics group, miR-146b-5p inhibitors NC group and miR-146b-5p inhibitors group, but not in blank group. All experimental data are expressed as mean $\pm \mathrm{SD}$ and each assay was performed in triplicate. ${ }^{* *} \mathrm{P}<0.01$ vs. blank group. GBC, gallbladder cancer; RT-qPCR, reverse transcription-quantitative PCR; GFP, green fluorescent protein.

In vivo xenograft model. Female SPF BALB/c nude mice (age, 6 weeks; weight, $18-22 \mathrm{~g}$ ) were provided by Nanjing Medical University Animal Laboratory (Nanjing, China). The animal experimental protocols were approved by the Institutional Animal Care and Use Committee of Southern Medical University (no. GZZL-2018-0235). The animals were housed 

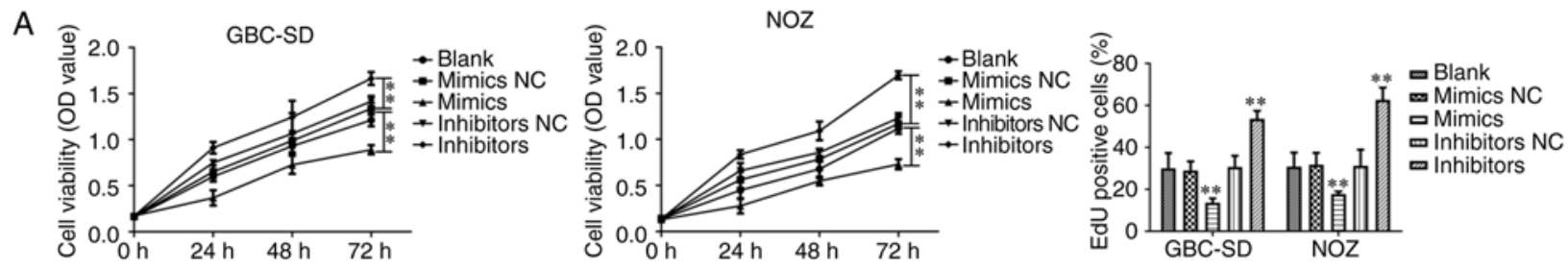

B

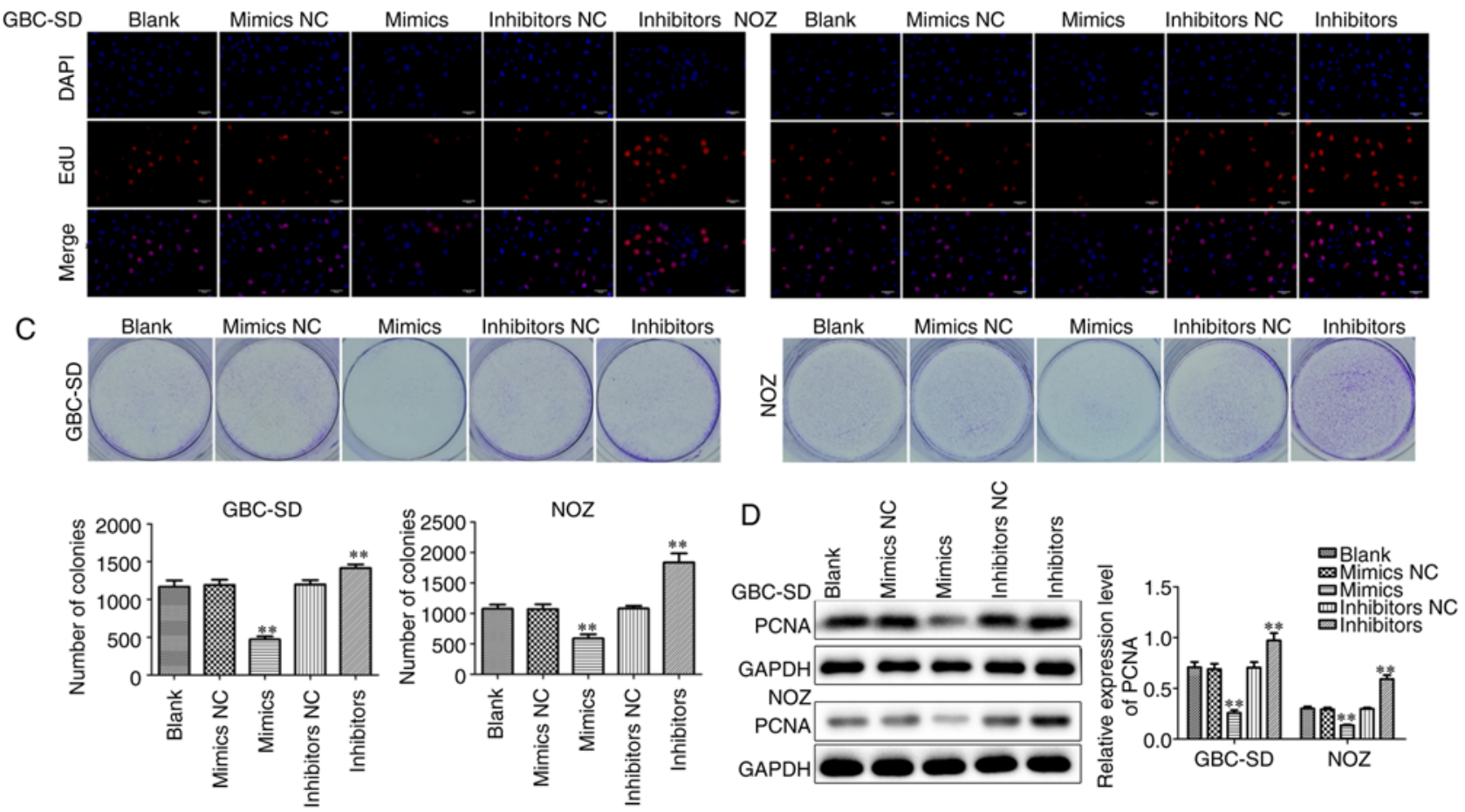

Figure 2. Effect of miR-146b-5p on the viability and proliferation of GBC cells. (A) The viability of GBC-SD and NOZ cells decreased in the miR-146b-5p mimics group in the CCK-8 assay, and inhibition of miR-146b-5p again increased cell viability. (B) EdU-positive nuclei indicated proliferating GBC-SD and NOZ cells in the different treatment groups (magnification, $x 200$ ). (C) Colony-forming assay revealed a higher proliferative capacity in the miR-146b-5p inhibitors group and a lower proliferative capacity in the miR-146b-5p mimics group in the GBC-SD and NOZ cell lines. (D) The expression of PCNA in GBC-SD and NOZ cells from different treatment groups was investigated with western blotting. All experimental data are expressed as mean \pm SD and each assay was performed in triplicate. ${ }^{* *} \mathrm{P}<0.01$ vs. blank group. GBC, gallbladder cancer; CCK-8, Cell Counting Kit-8; PCNA, proliferating cell nuclear antigen.

at room temperature $\left(18-25^{\circ} \mathrm{C}\right)$ with a 12 -h light/dark cycle and were given free access to a standard diet and tap water. The BALB/c nude mice were randomly divided into blank and experimental groups and weighed at the same time. GBC-SD cells transfected with miR-146b-5p mimic or miR-146b-5p mimic NC in the logarithmic growth phase were digested, centrifuged at $12,000 \mathrm{x} \mathrm{g}$ for $5 \mathrm{~min}$ at room temperature, the old culture medium was discarded and the cells were suspended in PBS. The cells were washed twice with PBS and mixed with Matrigel at a ratio of 1:1 (on ice) to adjust the cell density to $1 \times 10^{7} / \mathrm{ml}$. The single-cell suspension $\left(1 \times 10^{6}\right)$ was injected slowly into the axilla of nude mice. According to the humane endpoints, the mice were continuously observed for obvious decrease in activity, abnormal diet, emaciation and progressive weight loss, at which point they would have to be immediately anesthetized and sacrificed. None of the animals reached the humane endpoints before the conclusion of the study. During the experiments, animal health and behavior were monitored every 2 days and the size of tumors was measured every 3 days. At 30 days after injection, the mice were sacrificed by cervical dislocation after an intraperitoneal injection of sodium pentobarbital $(100 \mathrm{mg} / \mathrm{kg})$. Death was confirmed by observing lack of respiration and cardiac activity for $5 \mathrm{~min}$.

Statistical analysis. The results are presented as mean and standard error. Differences among multiple groups were analyzed by using one-way ANOVA followed by Tukey's post hoc test. Student's t-test was performed to evaluate statistical comparisons between two independent groups. Statistical analyses were performed using SPSS v19.0 (IBM Corp.). $\mathrm{P}<0.05$ was considered to indicate statistically significant differences.

\section{Results}

The expression of miR-146b-5p is decreased in GBC tissues and cells. Examination of 60 pairs of human GBC and normal tissues revealed a prominent decrease in miR-146b-5p expression in GBC tissues compared with that in normal tissues (Fig. 1A). Furthermore, when compared with gallbladder epithelial cells, the expression of miR-146b-5p in GBC cell lines was significantly lower (Fig. 1B). These results indicate that miR-146b-5p may play an important role in GBC. 

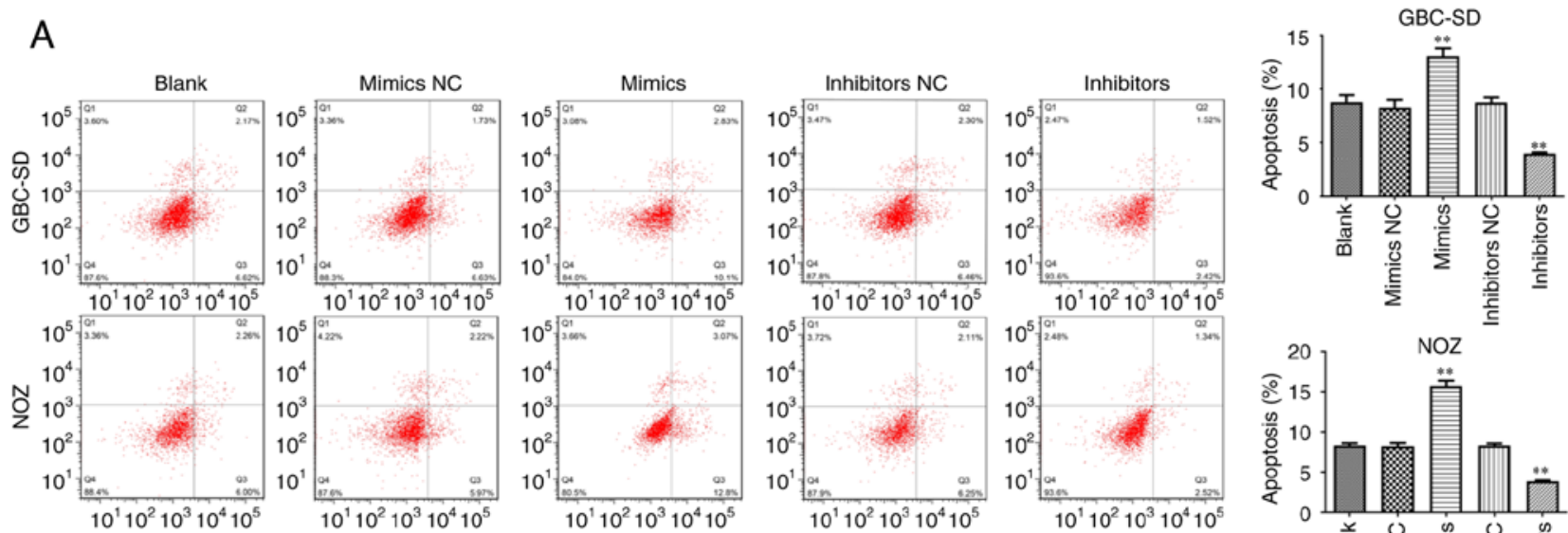

\section{B}
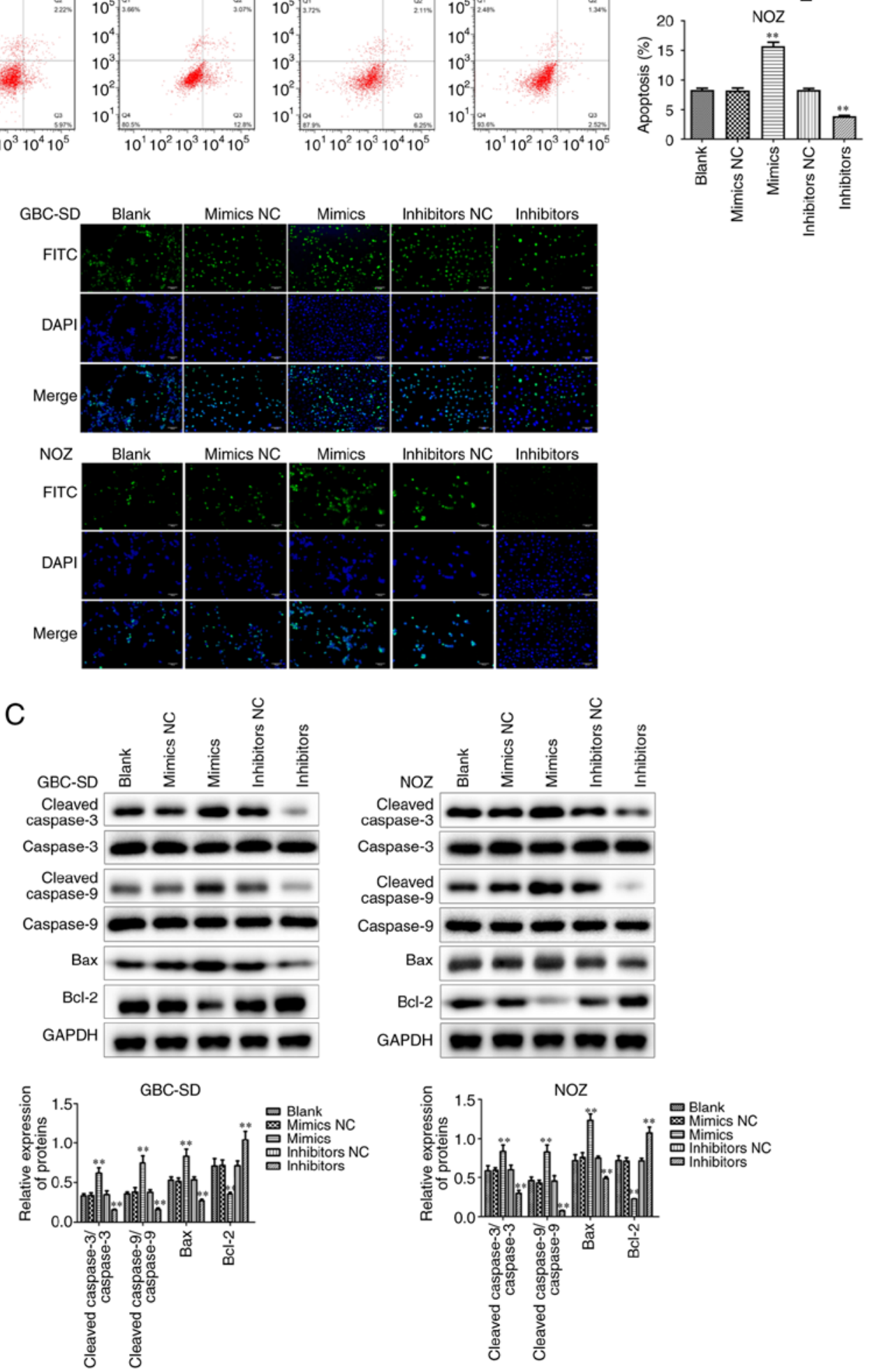

Figure 3. Effects of miR-146b-5p on the apoptosis of GBC cells. (A) Flow cytometry demonstrated that apoptosis increased in the miR-146b-5p mimics group, but decreased in the miR-146b-5p inhibitors group. (B) TUNEL staining was used to identify apoptotic cells. Overexpression of miR-146b-5p increased apoptosis in GBC-SD and NOZ cell lines (magnification, x200). (C) The expression level of the apoptosis-related proteins cleaved-caspase3, cleaved-caspase 9 , Bcl-2 and Bax in different treatment cells was investigated with western blotting. All experimental data are expressed as mean \pm SD and each assay was performed in triplicate. ${ }^{* *} \mathrm{P}<0.01$ vs. blank group. GBC, gallbladder cancer. 
A
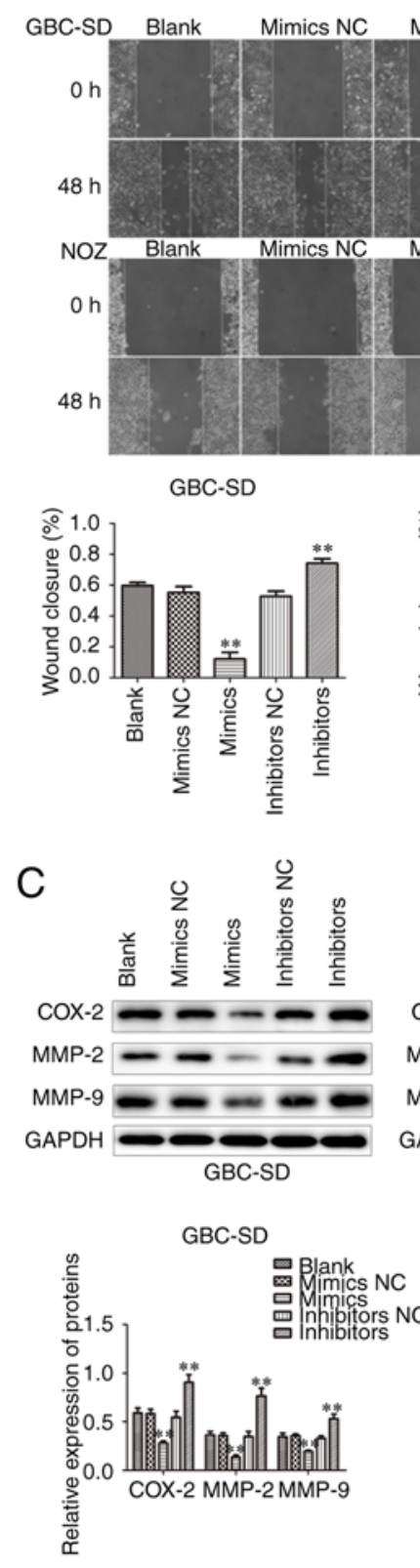

B

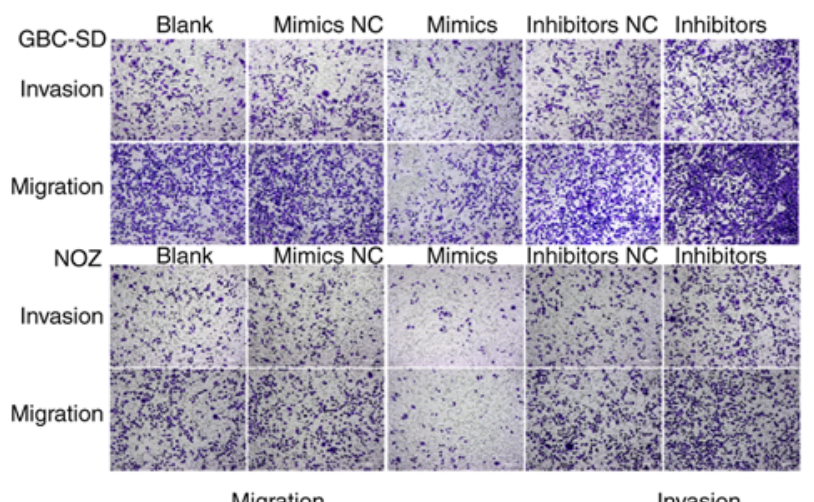

Migration
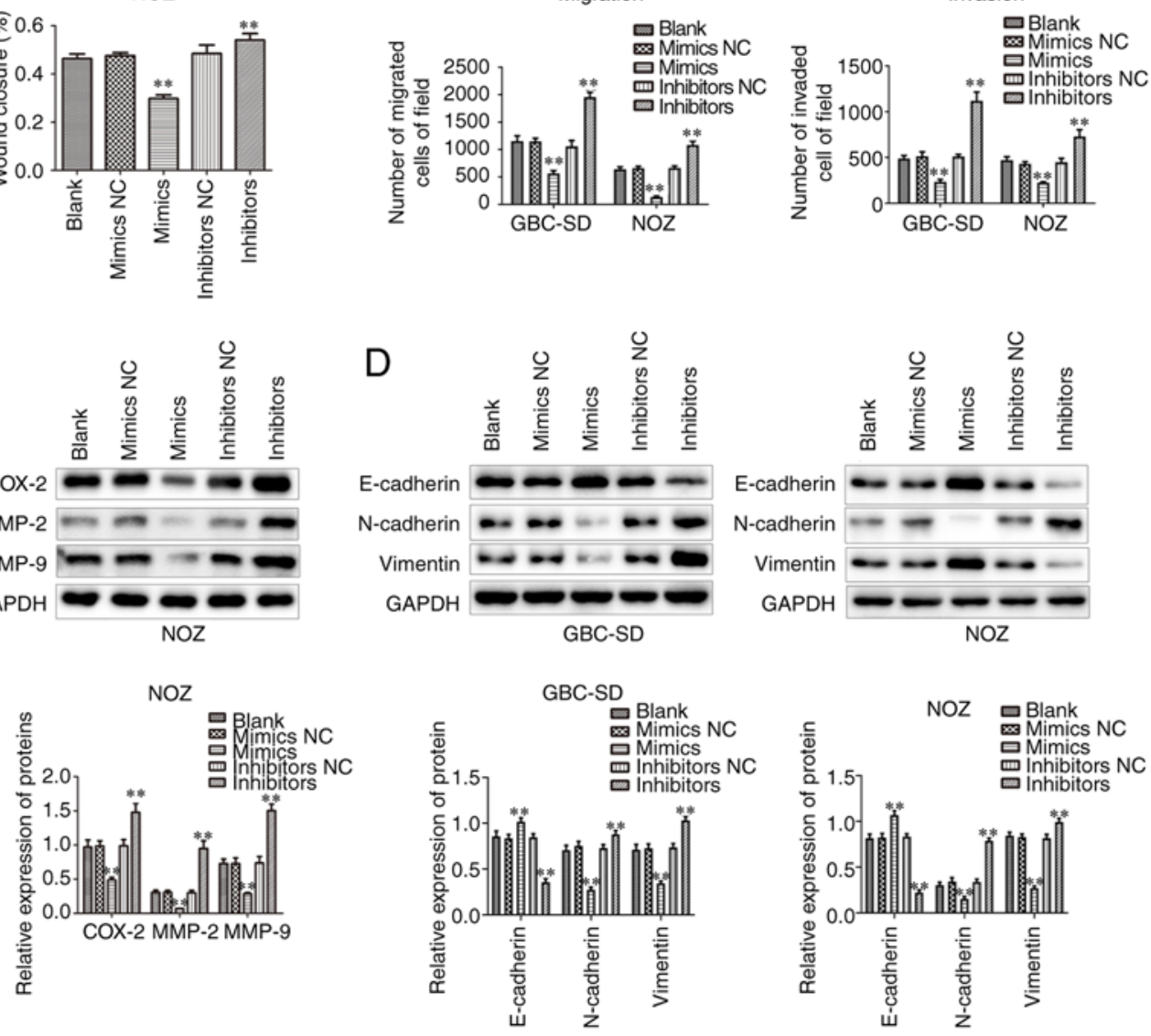

Figure 4. Effects of miR-146b-5p on the migration and invasion of GBC cells. (A and B) The migration and invasion of GBC-SD and NOZ cells in the miR-146b-5p inhibitor and miR-146b-5p mimic group were detected by wound healing assay and Transwell assay, respectively (magnification, $\mathrm{x} 200$ ). (C) Western blotting was used to investigate the expression levels of the invasion-related proteins MMP-2, MMP-9 and COX-2 in GBC-SD and NOZ cells in different treatment groups. (D) The protein expression of E-cadherin, N-cadherin and vimentin expression was assessed by western blotting All experimental data are expressed as mean \pm SD and each assay was performed in triplicate. ${ }^{* *} \mathrm{P}<0.01$ vs. blank group. GBC, gallbladder cancer; MMP, matrix metallopeptidase; COX, cyclo-oxygenase.

miR-146b-5p affects proliferation and apoptosis of GBC cells. To explore the role of miR-146b-5p in GBC, GBC cell lines were treated in vitro with miR-146b-5p mimics and miR-146b-5p inhibitors. RT-qPCR analysis and the GFP fluorescence reporter system were employed to confirm the efficiency of cell transfection (Fig. 1C and D). Then, the CCK-8 assay was used to detect cell viability, and it was observed that treatment with miR-146b-5p inhibitors can effectively increase cell viability; conversely, treatment with miR-146b-5p mimics resulted in decreased cell viability (Fig. 2A). These changes were the same in both GBC cell lines and lasted for at least $72 \mathrm{~h}$, suggesting a negative correlation between the expression level of miR-146b-5p and the viability of the GBC cells. Labeling proliferating cells with EdU demonstrated that overexpression of miR-146b-5p notably reduced, whereas inhibition of miR-146b-5p expression increased the number of EdU $^{+}$cells (Fig. 2B). By detecting the colony-forming ability of cells, it was observed that overexpression of miR-146b-5p reduced the number of colonies, whereas inhibiting the expression of miR-146b-5p increased colony formation (Fig. 2C). Proliferating cell nuclear antigen (PCNA), a marker of tumor cell deregulation, may be used to objectively evaluate tumor cell proliferation. It was observed that the expression of PCNA decreased following treatment with miR-146b-5p mimics, 
A

TLR4 5'-uggCUGUUUGAGAUGAGUUCUCu-3' ||: | ||: | ||||||| hsa-miR-146a-5p 5'-ucgGAU--ACCUUAAGUCAAGAGu-3'
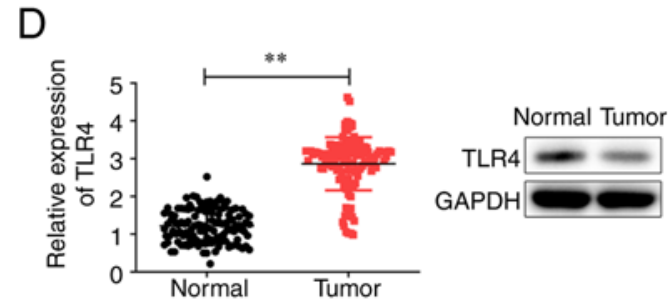

\section{F}

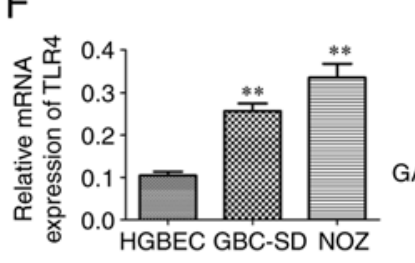

$\mathrm{H}$

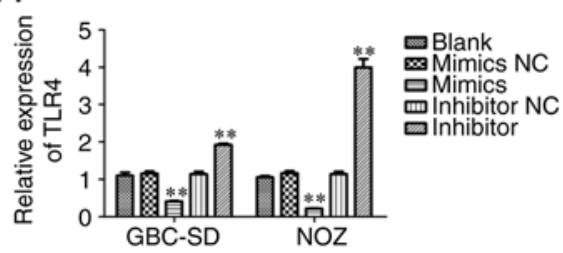

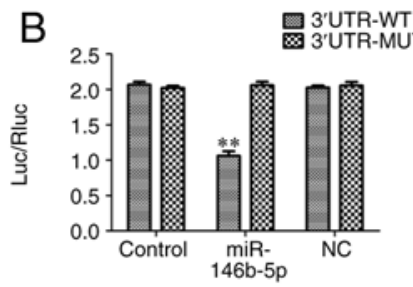
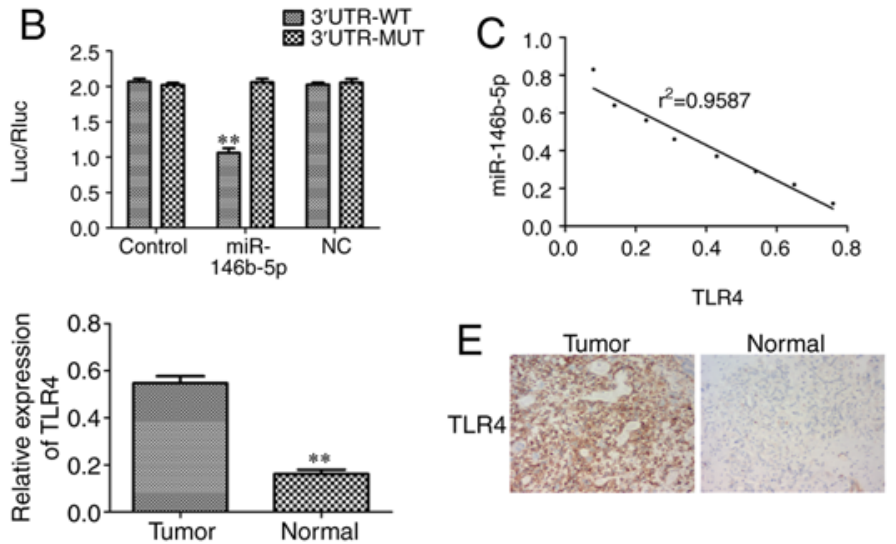

G
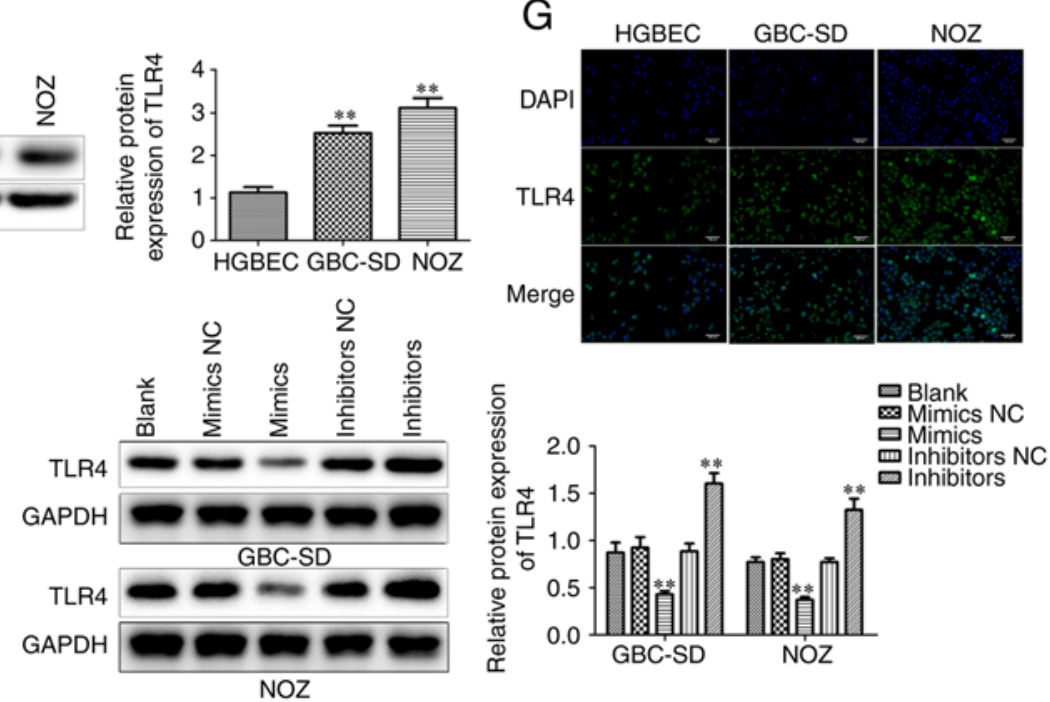

Figure 5. miR-146b-5p directly targets TLR4 in GBC tissues and cells. (A) Sequence alignment between miR-146b-5p and its target gene TLR4. (B) Luciferase activities of reporters containing the WT and MUT sequence of TLR4 in miR-146b-5p mimic NC cells and miR-146b-5p mimic cells. (C) There was a negative correlation between the expression of miR-146b-5p and TLR4. (D) RT-qPCR analysis and western blotting indicated an increase in the mRNA and protein level, respectively, of TLR4 in GBC tissues compared to normal tissues. (E) Immunohistochemical staining revealed differential expression of TLR4 between GBC and normal tissues. (F) RT-qPCR analysis and western blotting indicated an increase in mRNA and protein level, respectively, of TLR4 in GBC cells compared to gallbladder epithelial cells. (G) Immunofluorescence staining revealed differential expression of TLR4 between GBC cells and gallbladder epithelial cells (magnification, x200). (H) Overexpression of miR-146b-5p significantly reduced the mRNA and protein levels of TLR4, whereas inhibition of miR-146b-5p expression significantly increased the expression of TLR4. All experimental data are expressed as mean \pm SD and each assay was performed in triplicate. ${ }^{* *} \mathrm{P}<0.01$ vs. blank group. GBC, gallbladder cancer; TLR4, Toll-like receptor 4; RT-qPCR, reverse transcription-quantitative PCR; WT, wild-type; MUT, mutant.

while the expression of PCNA increased moderately following treatment with miR-146b-5p inhibitors (Fig. 2D). These data indicate that overexpression of miR-146b-5p inhibits the proliferation of GBC cells, while inhibiting the expression of miR-146b-5p increases GBC cell proliferation ability.

In addition to the abnormal proliferative capacity, apoptosis escape is also one of the reasons why tumor cells are difficult to eradicate. Flow cytometry displayed that miR-146b-5p overexpression markedly increased apoptosis of GBC cells (Fig. 3A), which was confirmed by TUNEL staining (Fig. 3B). Furthermore, it was observed that the expression of the pro-apoptotic factors Bax, cleaved-caspase-3 and cleaved-caspase- 9 increased, whereas the expression of the anti-apoptotic factor Bcl-2 decreased in the group treated with miR-146b-5p mimics (Fig. 3C). By contrast, when the expression of miR-146b-5p was inhibited, apoptosis of GBC cells also decreased. These results indicate that miR-146b-5p can inhibit cell proliferation and promote apoptosis in GBC cells in vitro.
miR-146b-5p affects migration and invasion of GBC cells. The migration and invasion abilities of cells under different treatments was next evaluated by Transwell and wound healing assays. It was observed that, when miR-146b-5p was overexpressed, the migration and invasion ability of GBC cells decreased. Conversely, inhibition of miR-146b-5p expression significantly increased cell migration and invasion ability (Fig. 4A and B). In addition, we observed that overexpression of miR-146b-5p signally reduced the expression of cell migration-associated proteins, such as MMP-2, MMP-9 and COX-2, but inhibiting the expression of miR-146b-5p significantly increased these protein expression levels of MMP-2, MMP-9 and COX-2 (Fig. 4C). Furthermore, miR-146b-5p overexpression reduced the protein expression of $\mathrm{N}$-cadherin and vimentin and increased the expression of E-cadherin (Fig. 4D). Collectively, these results indicate that miR-146b-5p overexpression inhibited the proliferation, migration and invasion of GBC cells and increased their apoptosis, suggesting that miR-146b-5p may be involved in occurrence and development of GBC. 

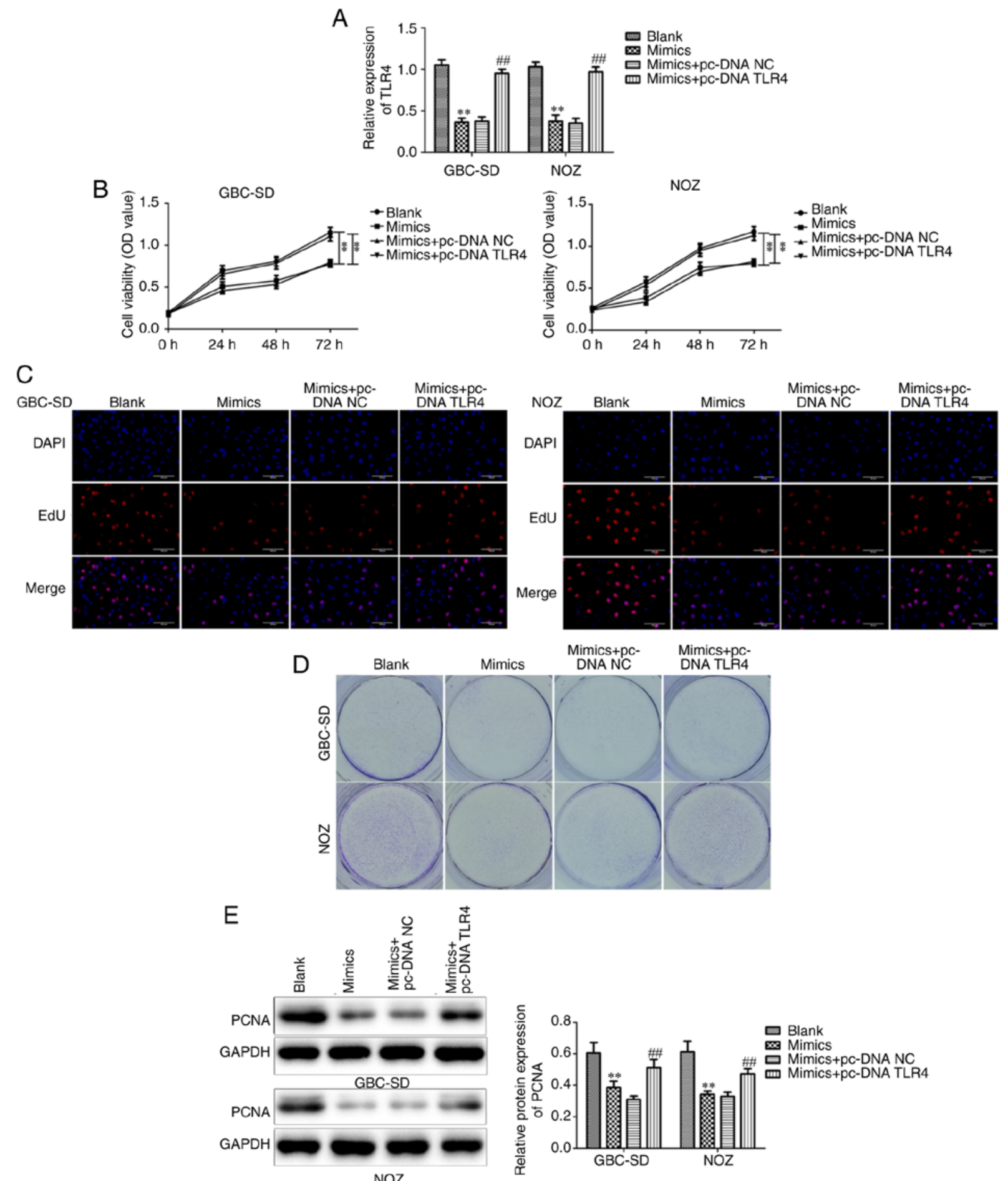

Figure 6. Overexpression of TLR4 restored cell proliferation affected by overexpression of miR-146b-5p. (A) The efficiency of overexpression of miR-146b-5p and TLR4 in two different GBC cell lines was assessed by reverse transcription-quantitative PCR analysis. (B-E) In the presence of overexpression of miR-146b-5p, TLR4 overexpression restored the decreased cell viability and proliferative capacity in the two GBC cell lines (magnification, x200). All experimental data are expressed as mean $\pm \mathrm{SD}$ and each assay was performed in triplicate. ${ }^{* *} \mathrm{P}<0.01 \mathrm{vs}$. blank group. ${ }^{\# \#} \mathrm{P}<0.01 \mathrm{vs}$. mimics + pc-DNA NC. GBC, gallbladder cancer; TLR4, Toll-like receptor 4; PCNA, proliferating cell nuclear antigen.

miR-146b-5p targets TLR4 in GBC tissues and cells. Although miR-146b-5p was found to play a crucial role regulatory role in GBC, the underlying mechanism remains elusive. Bioinformatics analysis revealed that TLR4 was target of miR-146b-5p and the mutated binding sites between TLR4 and miR-146b-5p were established (Fig. 5A). It was then observed by using luciferase reporter assay that TLR4 is a direct target gene of miR-146b-5p, whereas the mutated TLR4 was not degraded by miR-146b-5p (Fig. 5B). The Pearson curve distribution revealed a negative correlation between the expressions of miR-146b-5p and TLR4 (Fig. 5C). The mRNA and protein levels of TLR4 were found to be increased in human GBC tissues compared with those in normal tissues (Fig. 5D and E). Similarly, the mRNA and protein levels of TLR4 in GBC 
A

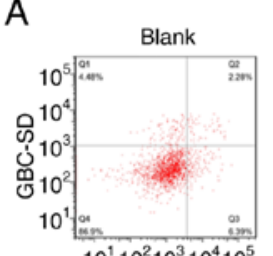

$10^{1} 10^{2} 10^{3} 10^{4} 10^{5}$

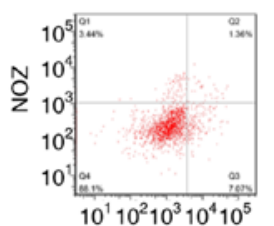$$
\text { . }
$$
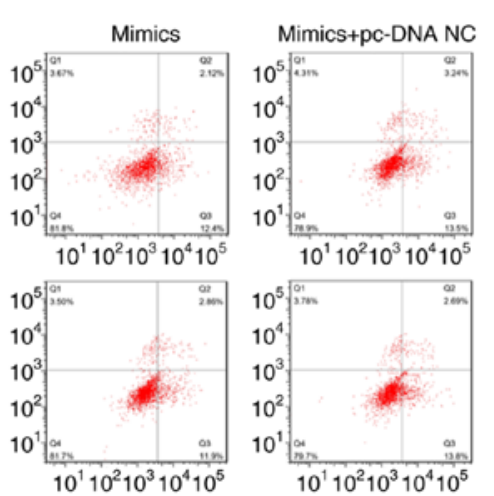

B
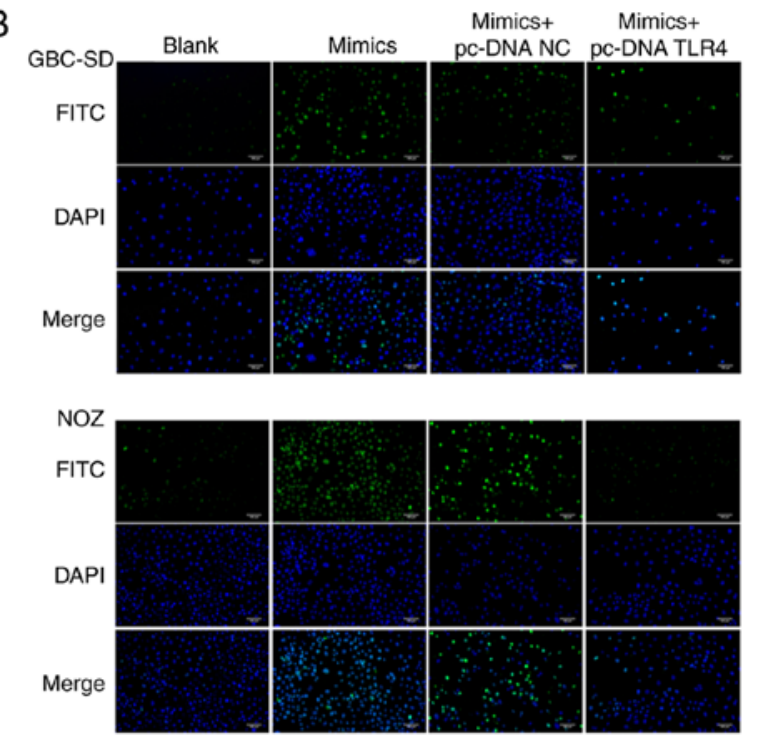

C
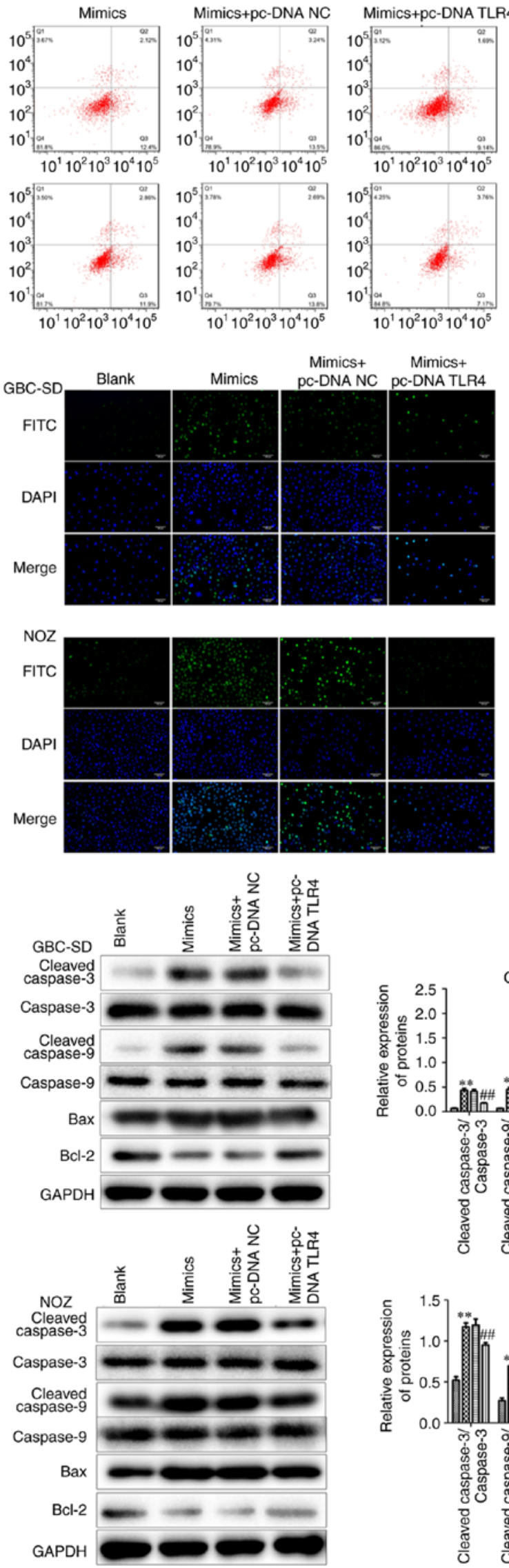
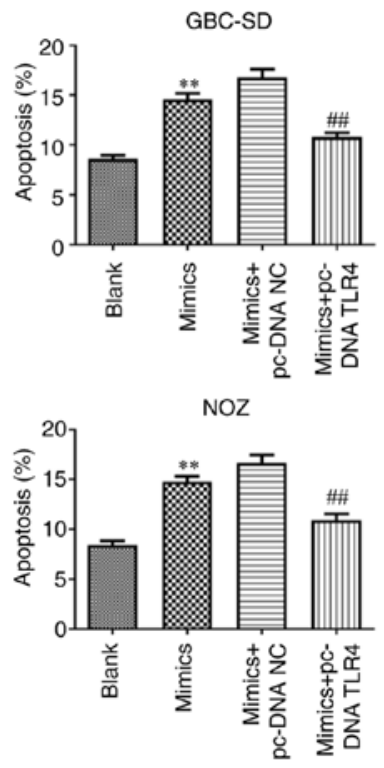

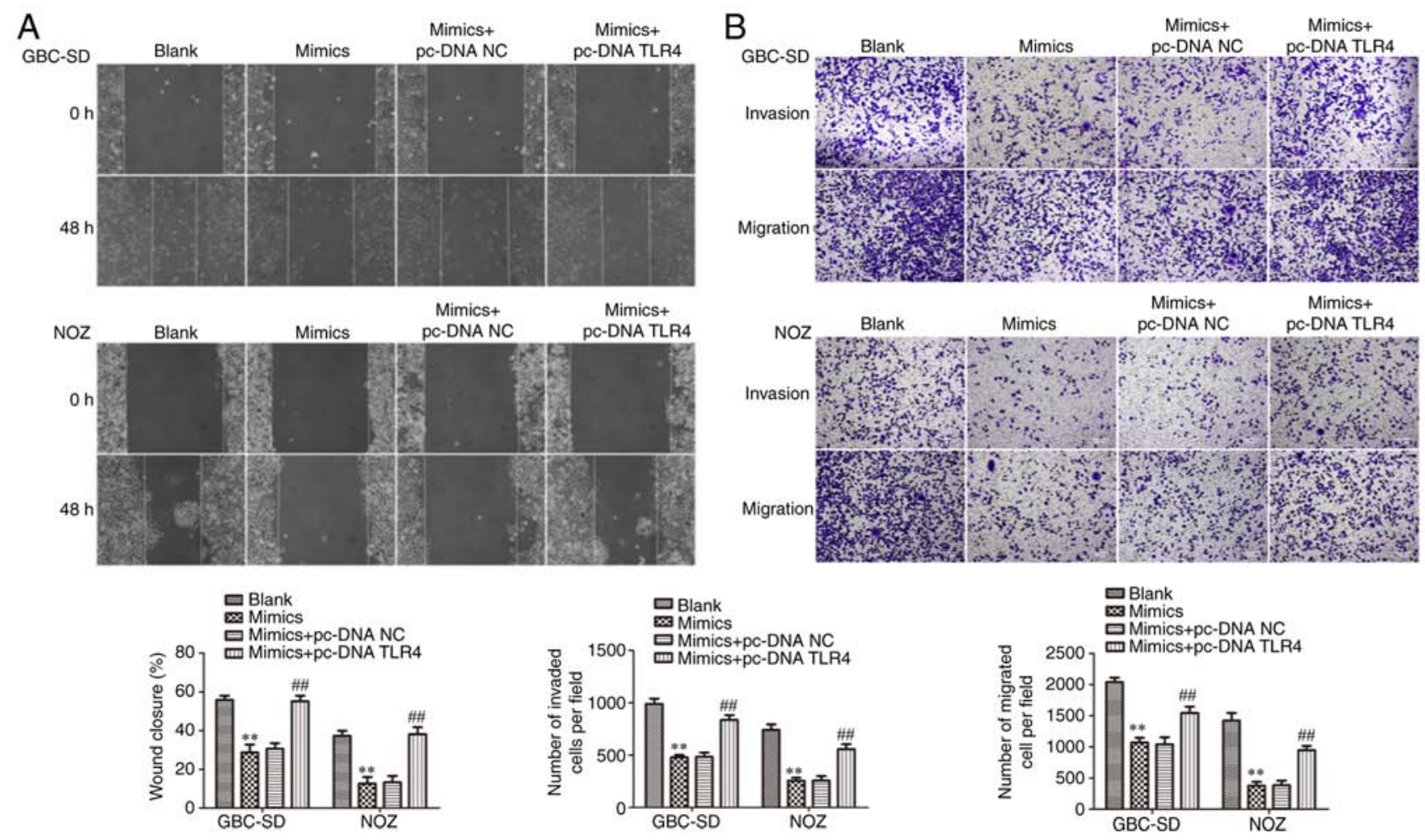

C

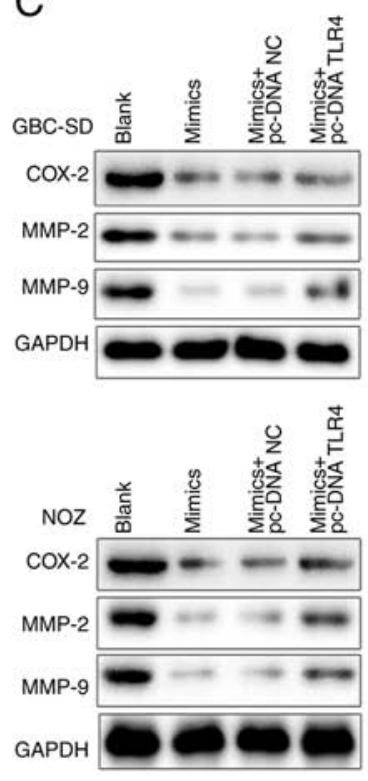

GBC-SD
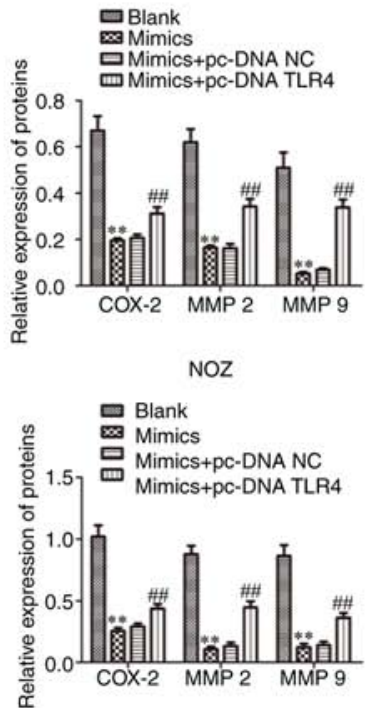
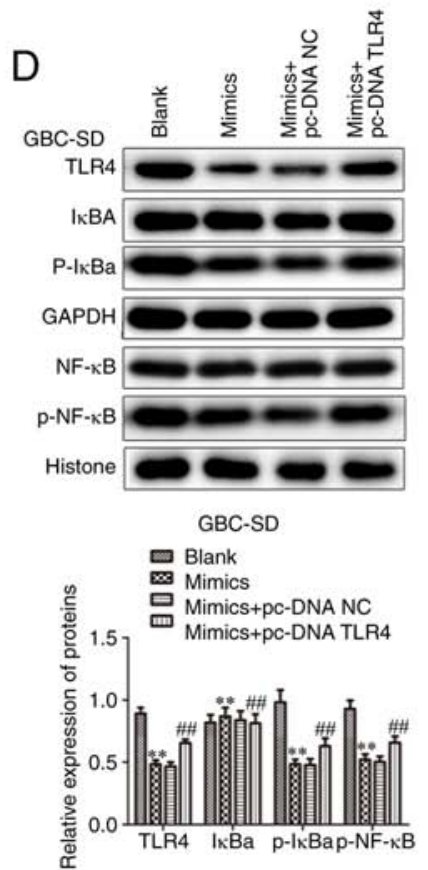
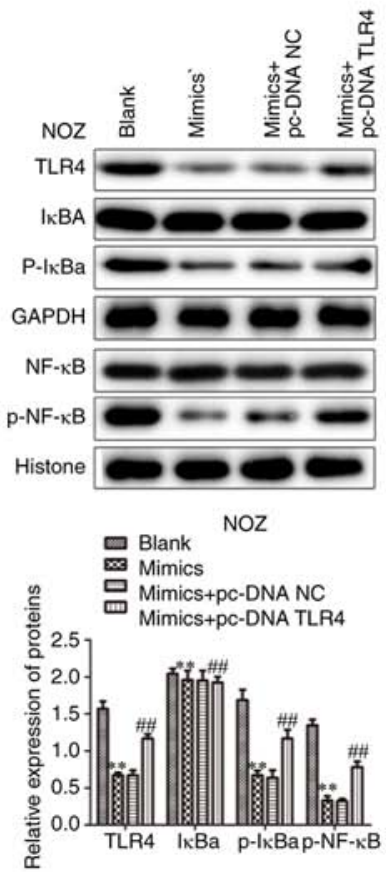

Figure 8. Overexpression of TLR4 restored cell migration and invasion affected by overexpression of miR-146b-5p. (A-C) In the presence of overexpression of miR-146b-5p, TLR4 overexpression restored decreased cell migration and invasion capacity in the two GBC cell lines (magnification, x200). (D) The expression level of activated NF-kB in the nucleus in different treatment groups was investigated with western blotting. All experimental data are expressed as mean $\pm \mathrm{SD}$ and each assay was performed in triplicate. ${ }^{* *} \mathrm{P}<0.01$ vs. blank group. ${ }^{\# \#} \mathrm{P}<0.01$ vs. mimics + pc-DNA NC. GBC, gallbladder cancer; TLR4, Toll-like

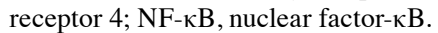

cell lines were higher compared with those in gallbladder epithelial cells (Fig. 5F and G). The miR-146b-5p inhibitor treatment group exhibited a significantly increased expression of TLR4 at both te mRNA and protein levels (Fig. 5H). The results mentioned above demonstrated that miR-146b-5p directly targets and negatively regulates TLR4, suggesting that miR-146b-5p may regulate GBC through TLR4.
Increased expression of TLR4 attenuates changes in GBC cells caused by overexpression of miR-146b-5p via the $N F-\kappa B$ signaling pathway. To verify whether changes in TLR4 expression levels are responsible for miR-146b-5p involvement in GBC, miR-146b-5p was overexpressed while increasing TLR4 expression levels (Fig. 6A). The results demonstrated that the decreased cell viability and proliferative capacity in the miR-146b-5p 

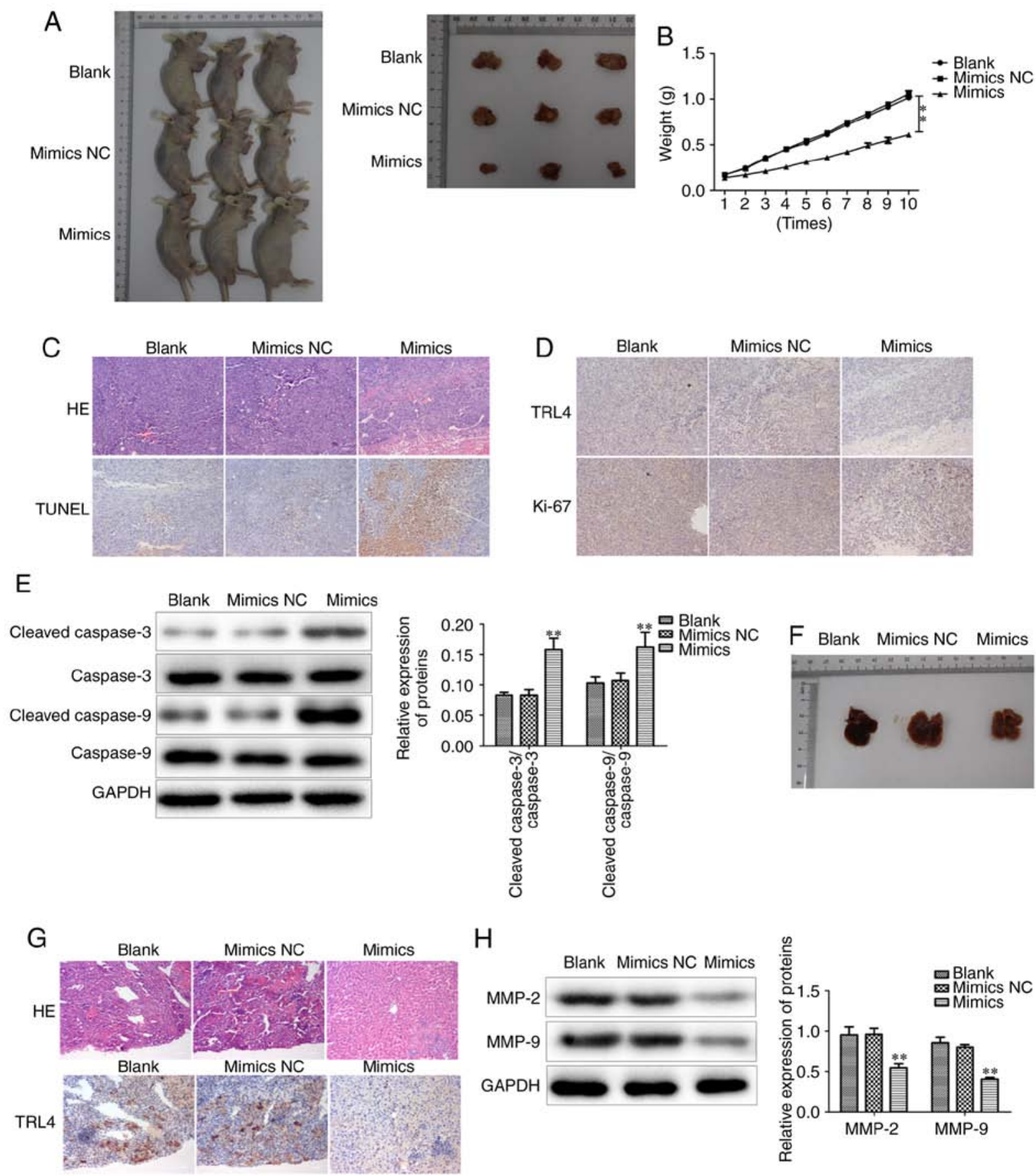

Figure 9. Overexpression of miR-146b-5p inhibited tumor growth and metastasis in vivo. (A and B) Volume and weight of xenograft tumors following injection of GBC cells from different treatment groups $(n=6)$. (C) Representative histological images of GBC tissues in mice, stained with HE. TUNEL staining was used to identify apoptotic cells in the tumors following injection of GBC cells from different treatment groups (magnification, x200). (D) Immunohistochemical staining for Ki-67 was used to identify mitotic figures among tumor cells (magnification, x200). (E) The expression level of the apoptosis-related proteins caspase-3 and caspase-9 in tumor tissues following injection of GBC cells from different treatment groups was investigated by western blotting. (F) Macroscopic comparison of liver metastatic tumors from mimics NC and mimics group. (G) HE staining of the metastatic tumor cells in liver tissues (magnification, x200). (H) Western blotting demonstrated the expression level of the MMP-2 and MMP-9 proteins in the different treatment groups. All experimental data are expressed as mean $\pm \mathrm{SD}$ and each assay was performed in triplicate. ${ }^{* *} \mathrm{P}<0.01 \mathrm{vs}$. blank group. GBC, gallbladder cancer; MMP, matrix metallopeptidase; HE, hematoxylin and eosin.

mimics-treated group of GBC cells recovered after overexpression of TLR4 (Fig. 6B-E). Conversely, the increased apoptosis in GBC cells in the miR-146b-5p mimics-treated group was significantly reduced after overexpression of TLR4 (Fig. 7A-C).

Furthermore, it was investigated whether TLR4 could reverse the decrease in the migration and invasion of GBC cells caused by overexpression of miR-146b-5p. Increased expression of TLR4 was found to attenuate the inhibition of migration and invasion of GBC cells caused by miR-146b-5p overexpression (Fig. 8A-C). These results suggest that increased TLR4 expression may reverse the changes in GBC cells caused by overexpression of miR-146b-5p.

It is well known that NF- $\mathrm{BB}$ is primarily involved in immune responses and inflammation, however, increasing 
evidence supports its pivotal role in tumorigenesis (38-41). The present study demonstrated that, after overexpressing miR-146b-5p, there was no significant change in cytoplasmic $\mathrm{I} \kappa \mathrm{B} \alpha$ levels, but the $\mathrm{p}-\mathrm{I} \kappa \mathrm{B} \alpha$ levels decreased, indicating a decrease in NF- $\mathrm{B}$ nuclear import. However, this change was restored after simultaneous overexpression of TLR4 (Fig. 8D). These results indicate that TLR4 may be involved in the regulation of GBC by increasing the phosphorylation of $N F-\kappa B$ and its transport into the nucleus to activate downstream target genes.

Overexpression of miR-146b-5p inhibits tumor growth and metastasis in vivo. To further investigate whether miR-146b-5p has the same effect in vivo, GBC-SD cells with different treatments were transplanted into BALB/c nude mice to observe tumor growth. It was observed that the tumors of the miR-146b-5p mimics-treated group had smaller volume and weight compared with those in the control group (Fig. 9A and $\mathrm{B})$. Hematoxylin and eosin (HE) staining demonstrated that overexpression of $\mathrm{miR}-146 \mathrm{~b}-5 \mathrm{p}$ reduced the aggressive phenotype of the tumor tissues (Fig. 9C). Furthermore, the proliferation and apoptosis of tumor cells were examined, and it was observed that the mouse tumors from cells treated with miR-146b-5p mimics exhibited higher cell apoptosis and lower proliferation rates compared with the control group (Fig. 9C-E).

Subsequently, tumor metastasis was evaluated by analyzing metastatic nodes in liver tissues at the end of the experiments. The results revealed that restoring miR-146b-5p expression significantly decreased liver metastasis in vivo (Fig. 9F), and HE staining confirmed a reduced number of metastatic tumor cells in liver tissue in miR-146b-5p mimics transfection group (Fig. 9G). In addition, the expression of MMP-2 and MMP-9 was found to be decreased in the miR-146b-5p mimics group (Fig. 9H). Collectively, these results indicate that miR-146b-5p inhibits the growth and aggressiveness of xenografted tumors in BALB/c nude mice, and upregulating miR-146b-5p expression inhibits GBC liver metastasis in vivo, suggesting that it may represent an effective target for the treatment of GBC.

\section{Discussion}

The present study demonstrated that human GBC tissues exhibited lower expression level of miR-146b-5p compared with normal tissue, and its expression level was correlated with clinicopathological characteristics. Inhibiting the expression level of miR-146b-5p in GBC cells cultured in vitro significantly increased cell viability, proliferation, migration and invasion, and reduced cell apoptosis. Conversely, overexpression of miR-146b-5p inhibited GBC cell viability, proliferative and invasive ability, and increased apoptosis. Bioinformatics analysis and prediction identified TLR4 as a miR-146b-5p target, which was confirmed by our results. In addition, a significant increase in the expression level of TLR4 in human GBC tissues was detected. Overexpression of TLR4 alleviated inhibition of GBC cell characteristics caused by overexpression of miR-146b-5p. Furthermore, it was observed that, after overexpression of miR-146b-5p, the level of $\mathrm{p}-\mathrm{I} \kappa \mathrm{B} \alpha$ in the cytoplasm decreased, while the expression level of $\mathrm{p}-\mathrm{NF}-\kappa \mathrm{B}$ in the nucleus increased, and these changes were inhibited by simultaneously overexpressing TLR4. This may uncover the mechanism through which miR-146b-5p is involved in the regulation of the development of GBC. The BALB/c nude mouse xenograft experiments also demonstrated that miR-146b-5p reduces tumor growth in vivo by inhibiting cell proliferation and promoting cell apoptosis. Taken together, these results indicate that upregulating the expression of miR-146b-5p may be a new and valuable clinical approach to the treatment of GBC.

As the fifth most usual gastrointestinal cancer globally, GBC has a clear regional bias (42). In addition, in some high-prevalence areas of GBC, the incidence of women is 2.3 times that of men, suggesting the effect of sex on GBC susceptibility $(43,44)$. It was previously demonstrated that estrogen increases the risk of developing cholesterol gallstones to some extent, and the supersaturation of cholesterol in the bile participates in the development of GBC through gallstone-mediated mechanisms (45); however, this is questioned by other research groups (46). It was also reported that some cancers differ at the molecular level between sexes, including small RNA levels (47). Differences in expression of sex-dependent small RNAs are prevalent in mammals and birds (48-52). We herein demonstrated that human GBC tissues express lower levels of miR-146b-5p compared with normal tissues. It is not clear whether the expression of microRNA-146b-5p is also affected by sex, and this association requires further investigation of a larger number of samples.

The majority of patients with GBC are often diagnosed in the late stages of the disease, due in part to the lack of reliable tumor markers. Thus far, only two markers, namely carcinoembryonic antigen (CEA) and carbohydrate antigen 19-9, have been detected in late-stage GBC, but their specificity is poor (53). Therefore, it is necessary to identify biomarkers that can quickly and accurately diagnose GBC. Although other groups have also investigated the possibility of different markers of other types of tumors as markers of GBC, the results reported are highly inconsistent (54-56). Some research groups have tried to analyze the GBC genome in an attempt to find a way to diagnose and treat GBC, but with little success (57). There is increasing evidence that circulating miRNAs secreted by pathological tissues into the humoral circulation system may serve as markers for early diagnosis of diseases, such as myocardial infarction, endocrine cancer and coronary artery disease (58-61). By examining blood samples, it may be possible to analyze the difference in the expression level of miR-146b-5p, which may prove to be an effective method for clinical diagnosis of early GBC.

A variety of inflammatory mediators released during chronic inflammation have been shown to induce DNA methylation and post-translational modification of proto-oncogenes and/or tumor suppressor genes (62). The effects of DNA methylation modifications on GBC have been extensively investigated. It has been demonstrated that the expression level of TLR4 is observably enhanced in human GBC tissues, and that activation of TLR4 signaling leads to an excessive inflammatory response (63). The present study confirmed that TLR4 is a direct target gene of miR-146b-5p (Fig. 5). The long-term overactivation of TLR4 involved in inflammation, which is negatively regulated by miR-146b-5p, may be among the main causes of GBC occurrence and development. This 
finding constitutes powerful evidence that miR-146b-5p may be a useful biomarker for the clinical diagnosis of early GBC.

In summary, the present study demonstrated that miR-146b-5p is involved in the regulation of $\mathrm{GBC}$, and that overexpression of miR-146b-5p may reduce the expression of its target gene, TLR4, thereby inhibiting the sustained activation of $\mathrm{NF}-\kappa \mathrm{B}$. Furthermore, overexpression of miR-146b-5p in vivo may partially reduce GBC volume and suppress the aggressive phenotypical characteristics. However, the development of GBC may be a multi-factorial process, and further research is required to elucidate whether it involves more complicated regulatory mechanisms.

\section{Acknowledgements}

Not applicable.

\section{Funding}

The present study was supported by Nanjing Medical Science and technique Development Foundation (grant no. QRX17105).

\section{Availability of data and materials}

The datasets used and/or analyzed during the present study are available from the corresponding author on reasonable request.

\section{Authors' contributions}

WJ designed the experiments. BO was the major contributor to writing the manuscript. NP, HZ and CX performed the experiments. All the authors have read and approved the final version of the manuscript for publication.

\section{Ethics approval and consent to participate}

Informed patient consent for participation was obtained at the time of the study. The present study was approved by the Ethics Committee of Southern Medical University (no. 2018-SR-052). The animal experimental protocols were approved by the Institutional Animal Care and Use Committee of Southern Medical University (no. GZZL-2018-0235).

\section{Patient consent for publication}

Not applicable.

\section{Competing interests}

All the authors declare that they have no competing interests.

\section{References}

1. Misra S, Chaturvedi A, Misra NC and Sharma ID: Carcinoma of the gallbladder. Lancet Oncol 4: 167-176, 2003.

2. Andia ME, Hsing AW, Andreotti G and Ferreccio C: Geographic variation of gallbladder cancer mortality and risk factors in Chile: A population-based ecologic study. Int J Cancer 123: 1411-1416, 2008

3. Pilgrim CH, Groeschl RT, Christians KK and Gamblin TC: Modern perspectives on factors predisposing to the development of gallbladder cancer. HPB (Oxford) 15: 839-844, 2013.

4. Iyer P, Barreto SG, Sahoo B, Chandrani P, Ramadwar MR, Shrikhande SV and Dutt A: Non-typhoidal Salmonella DNA traces in gallbladder cancer. Infect Agent Cancer 11: 12, 2016.
5. Jain K, Sreenivas V, Velpandian T, Kapil U and Garg PK: Risk factors for gallbladder cancer: A case-control study. Int J Cancer 132: 1660-1666, 2013.

6. Hundal R and Shaffer EA: Gallbladder cancer: Epidemiology and outcome. Clin Epidemiol 6: 99-109, 2014.

7. Yang XW, Yang J, Li L, Man XB, Zhang BH, Shen F and Wu MC: Analysis of the relationships between clinicopathologic factors and survival in gallbladder cancer following surgical resection with curative intent. PLoS One 7: e51513, 2012.

8. Sasatomi E, Tokunaga O and Miyazaki K: Precancerous conditions of gallbladder carcinoma: Overview of histopathologic characteristics and molecular genetic findings. J Hepatobiliary Pancreat Surg 7: 556-567, 2000.

9. Rashid A: Cellular and molecular biology of biliary tract cancers. Surg Oncol Clin N Am 11: 995-1009, 2002.

10. Mo YY: MicroRNA regulatory networks and human disease. Cell Mol Life Sci 69: 3529-3531, 2012.

11. Jovanovic $M$ and Hengartner MO: miRNAs and apoptosis: RNAs to die for. Oncogene 25: 6176-6187, 2006.

12. Farazi TA, Spitzer JI, Morozov P and Tuschl T: miRNAs in human cancer. J Pathol 223: 102-115, 2011.

13. Johnson CD, Esquela-Kerscher A, Stefani G, Byrom M, Kelnar K, Ovcharenko D, Wilson M, Wang X, Shelton J, Shingara J, et al: The let-7 microRNA represses cell proliferation pathways in human cells. Cancer Res 67: 7713-7722, 2007.

14. Inui M, Martello G and Piccolo S: MicroRNA control of signal transduction. Nat Rev Mol Cell Biol 11: 252-263, 2010.

15. Okayama H, Schetter AJ and Harris CC: MicroRNAs and inflammation in the pathogenesis and progression of colon cancer. Dig Dis 30 (Suppl 2): S9-S15, 2012.

16. Schetter AJ, Heegaard NH and Harris CC: Inflammation and cancer: Interweaving microRNA, free radical, cytokine and p53 pathways. Carcinogenesis 31: 37-49, 2010.

17. Kono H, Nakamura M, Ohtsuka T, Nagayoshi Y, Mori Y, Takahata S, Aishima S and Tanaka M: High expression of microRNA-155 is associated with the aggressive malignant behavior of gallbladder carcinoma. Oncol Rep 30: 17-24, 2013.

18. Letelier P, García P, Leal P, Álvarez H, Ili C, López J, Castillo J, Brebi P and Roa JC: miR-1 and miR-145 act as tumor suppressor microRNAs in gallbladder cancer. Int J Clin Exp Pathol 7: 1849-1867, 2014.

19. Zhou H, Wang Y, Zha R, Ding J, Liang L, Hu J, Shen H, Chen Z, Guo W, Zhao Y, et al: MicroRNA-26a acts as a tumor suppressor inhibiting gallbladder cancer cell proliferation by directly targeting HMGA2. Int J Oncol 44: 2050-2058, 2014.

20. Zhou H, Guo W, Zhao Y, Wang Y, Zha R, Ding J, Liang L, Yang G, Chen Z, Ma B and Yin B: MicroRNA-135a acts as a putative tumor suppressor by directly targeting very low density lipoprotein receptor in human gallbladder cancer. Cancer Sci 105: 956-965, 2014.

21. Peng HH, Zhang YD, Gong LS, Liu WD and Zhang Y: Increased expression of microRNA-335 predicts a favorable prognosis in primary gallbladder carcinoma. Onco Targets Ther 6: 1625-1630, 2013.

22. Yoon SO, Kim EK, Lee M, Jung WY, Lee H, Kang Y, Jang YJ, Hong SW, Choi SH and Yang WI: NOVA1 inhibition by miR-146b-5p in the remnant tissue microenvironment defines occult residual disease after gastric cancer removal. Oncotarget 7: 2475-2495, 2016.

23. Deng $X, W u$ B, Xiao K, Kang J, Xie J, Zhang $X$ and Fan Y: MiR-146b-5p promotes metastasis and induces epithelial-mesenchymal transition in thyroid cancer by targeting ZNRF3. Cell Physiol Biochem 35: 71-82, 2015.

24. Xu E, Zhao J, Ma J, Wang C, Zhang C, Jiang H, Cheng J, Gao R and Zhou X: miR-146b-5p promotes invasion and metastasis contributing to chemoresistance in osteosarcoma by targeting zinc and ring finger 3. Oncol Rep 35: 275-283, 2016.

25. Liu J, Xu J, Li H, Sun C, Yu L, Li Y, Shi C, Zhou X, Bian X, Ping Y, et al: miR-146b-5p functions as a tumor suppressor by targeting TRAF6 and predicts the prognosis of human gliomas. Oncotarget 6: 29129-29142, 2015.

26. Cai J, Xu L, Cai Z, Wang J, Zhou B and Hu H: MicroRNA-146b-5p inhibits the growth of gallbladder carcinoma by targeting epidermal growth factor receptor. Mol Med Rep 12: 1549-1555, 2015.

27. Byrd-Leifer CA, Block EF, Takeda K, Akira S and Ding A: The role of MyD88 and TLR4 in the LPS-mimetic activity of Taxol. Eur J Immunol 31: 2448-2457, 2001

28. Huang JM, Zhang GN, Shi Y, Zha X, Zhu Y, Wang MM, Lin Q, Wang W, Lu HY, Ma SQ, et al: Atractylenolide-I sensitizes human ovarian cancer cells to paclitaxel by blocking activation of TLR4/MyD88-dependent pathway. Sci Rep 4: 3840, 2014. 
29. Kawasaki $\mathrm{T}$ and Kawai T: Toll-like receptor signaling pathways. Front Immunol 5: 461, 2014.

30. Wang AC, Ma YB, Wu FX, Ma ZF, Liu NF, Gao R, Gao YS and Sheng XG: TLR4 induces tumor growth and inhibits paclitaxel activity in MyD88-positive human ovarian carcinoma in vitro. Oncol Lett 7: 871-877, 2014.

31. Kawasaki K, Akashi S, Shimazu R, Yoshida T, Miyake K and Nishijima M: Mouse toll-like receptor 4.MD-2 complex mediates lipopolysaccharide-mimetic signal transduction by Taxol. J Biol Chem 275: 2251-2254, 2000.

32. Rajput S, Volk-Draper LD and Ran S: TLR4 is a novel determinant of the response to paclitaxel in breast cancer. Mol Cancer Ther 12: 1676-1687, 2013.

33. Tichomirowa MA, Theodoropoulou M, Daly AF, Yassouridis A, Hansen S, Lu J, Lange M, Goldbrunner RH, Stalla GK and Renner U: Toll-like receptor-4 is expressed in meningiomas and mediates the antiproliferative action of paclitaxel. Int J Cancer 123: 1956-1963, 2008.

34. Ustinova EE, Shurin GV, Gutkin DW and Shurin MR: The role of TLR4 in the paclitaxel effects on neuronal growth in vitro. PLoS One 8: e56886, 2013.

35. Ran S: The role of TLR4 in chemotherapy-driven metastasis. Cancer Res 75: 2405-2410, 2015.

36. Volk-Draper L, Hall K, Griggs C, Rajput S, Kohio P, DeNardo D and Ran S: Paclitaxel therapy promotes breast cancer metastasis in a TLR4-dependent manner. Cancer Res 74: 5421-5434, 2014.

37. Haricharan S and Brown P: TLR4 has a TP53-dependent dual role in regulating breast cancer cell growth. Proc Natl Acad Sci USA 112: E3216-E3225, 2015.

38. Bonizzi G and Karin M: The two NF-kappaB activation pathways and their role in innate and adaptive immunity. Trends Immunol 25: 280-288, 2004.

39. Hayden MS and Ghosh S: Signaling to NF-kappaB. Genes Dev 18: 2195-2224, 2004.

40. Greten FR and Karin M: The IKK/NF-kappaB activation pathway-a target for prevention and treatment of cancer. Cancer Lett 206: 193-199, 2004.

41. Cogswell PC, Guttridge DC, Funkhouser WK and Baldwin AS Jr: Selective activation of NF-kappa B subunits in human breast cancer: Potential roles for NF-kappa B2/p52 and for Bcl-3. Oncogene 19: 1123-1131, 2000

42. Boutros C, Gary M, Baldwin K and Somasundar P: Gallbladder cancer: Past, present and an uncertain future. Surg Oncol 21: e183-e191, 2012.

43. Randi G, Franceschi S and La Vecchia C: Gallbladder cancer worldwide: Geographical distribution and risk factors. Int J Cancer 118: 1591-1602, 2006.

44. Lazcano-Ponce EC, Miquel JF, Muñoz N, Herrero R, Ferrecio C, Wistuba II, Alonso de Ruiz P, Aristi Urista G and Nervi F: Epidemiology and molecular pathology of gallbladder cancer. CA Cancer J Clin 51: 349-364, 2001.

45. Everson GT, McKinley C and Kern F Jr: Mechanisms of gallstone formation in women. Effects of exogenous estrogen (Premarin) and dietary cholesterol on hepatic lipid metabolism. J Clin Invest 87: 237-246, 1991.

46. Barreto SG, Haga $\mathrm{H}$ and Shukla PJ: Hormones and gallbladder cancer in women. Indian J Gastroenterol 28: 126-130, 2009.

47. Yuan Y, Liu L, Chen H, Wang Y, Xu Y, Mao H, Li J, Mills GB, Shu Y, Li L and Liang H: Comprehensive characterization of molecular differences in cancer between male and female patients. Cancer Cell 29: 711-722, 2016.
48. Warnefors M, Mössinger K, Halbert J, Studer T, VandeBerg JL, Lindgren I, Fallahshahroudi A, Jensen P and Kaessmann H: Sex-biased microRNA expression in mammals and birds reveals underlying regulatory mechanisms and a role in dosage compensation. Genome Res 27: 1961-1973, 2017.

49. Guo L, Zhang Q, Ma X, Wang J and Liang T: miRNA and mRNA expression analysis reveals potential sex-biased miRNA expression. Sci Rep 7: 39812, 2017.

50. Duttagupta R, Jiang R, Gollub J, Getts RC and Jones KW: Impact of cellular miRNAs on circulating miRNA biomarker signatures. PLoS One 6: e20769, 2011.

51. Wang K, Yuan Y, Cho JH, McClarty S, Baxter D and Galas DJ: Comparing the MicroRNA spectrum between serum and plasma. PLoS One 7: e41561, 2012.

52. Langevin SM, Stone RA, Bunker CH, Grandis JR, Sobol RW and Taioli E: MicroRNA-137 promoter methylation in oral rinses from patients with squamous cell carcinoma of the head and neck is associated with gender and body mass index. Carcinogenesis 31: 864-870, 2010.

53. Srivastava K, Srivastava A and Mittal B: Potential biomarkers in gallbladder cancer: Present status and future directions. Biomarkers 18: 1-9, 2013.

54. He CZ, Zhang KH, Li Q, Liu XH, Hong Y and Lv NH: Combined use of AFP, CEA, CA125 and CA19-9 improves the sensitivity for the diagnosis of gastric cancer. BMC Gastroenterol 13: 87, 2013.

55. Zur B, Holdenrieder S, Walgenbach-Brünagel G, Albers E and Stoffel-Wagner B: Method comparison for determination of the tumor markers AFP, CEA, PSA and free PSA between Immulite 2000 XPI and Dimension Vista 1500. Clin Lab 58: 97-105, 2012.

56. Zhang D, Yu M, Xu T and Xiong B: Predictive value of serum CEA, CA19-9 and CA125 in diagnosis of colorectal liver metastasis in Chinese population. Hepatogastroenterology 60: 1297-1301, 2013

57. Sicklick JK, Fanta PT, Shimabukuro K and Kurzrock R: Genomics of gallbladder cancer: The case for biomarker-driven clinical trial design. Cancer Metastasis Rev 35: 263-275, 2016.

58. Olivieri F, Antonicelli R, Capogrossi MC and Procopio AD: Circulating microRNAs (miRs) for diagnosing acute myocardial infarction: An exciting challenge. Int J Cardiol 167: 3028-3029, 2013.

59. Zhao S, Yan L and Zhao Z: Up-regulation of miR-203 inhibits the growth of cervical cancer cells by inducing cell cycle arrest and apoptosis. Eur J Gynaecol Oncol 40: 791-795, 2019.

60. Fichtlscherer S, De Rosa S, Fox H, Schwietz T, Fischer A, Liebetrau C, Weber M, Hamm CW, Röxe T, Müller-Ardogan M, et al: Circulating microRNAs in patients with coronary artery disease. Circ Res 107: 677-684, 2010.

61. Keller A and Meese E: Can circulating miRNAs live up to the promise of being minimal invasive biomarkers in clinical settings? Wiley Interdiscip Rev RNA 7: 148-156, 2016.

62. Hussain SP and Harris CC: Inflammation and cancer: An ancient link with novel potentials. Int J Cancer 121: 2373-2380, 2007.

63. Mara MA, Good M and Weitkamp JH: Innate and adaptive immunity in necrotizing enterocolitis. Semin Fetal Neonatal Med 23: 394-399, 2018.

This work is licensed under a Creative Commons Attribution-NonCommercial-NoDerivatives 4.0 International (CC BY-NC-ND 4.0) License. 